\title{
Anionic N-Fries Rearrangement of N-alkyl-2-iodo Anilides Induced by Iodine-magnesium Exchange: Application for Synthesis of Strained 1,2,3-Trisubstituted Indoles
}

\author{
Fei Ding, Yongda Zhang, Bo Qu, Guisheng Li, Vittorio Farina, Bruce Z. \\ $\mathrm{Lu}^{*}$ and Chris H. Senanayake \\ Department of Chemical Development, Boehringer-Ingelheim Pharmaceuticals, Inc., \\ Ridgefield, Connecticut 06877
}

\section{Supporting Information}

General Methods. All reactions were carried out under an atmosphere of argon in dry glassware with magnetic stirring. Commercially available anhydrous tetrahydrofuran, Nmethylpyrrolidinone and N, N-dimethylformamide are received from Aldrich and used without any further purification. Column chromatography was performed on EM Science silica gel 60 (230-400 mesh). Thin layer chromatography was performed on EM Science $0.25 \mathrm{~mm}$ silica gel 60-F plates. Visualization was accomplished with $\mathrm{UV}$ light, $\mathrm{KMnO}_{4}$, aqueous ceric ammonium molybdate, or bromocresol green dips followed by heating.

Melting points were measured with a MelTemp II melting point apparatus outfitted with a Fluke 51 thermocouple and are uncorrected. Infrared spectra were obtained on a NEXUS 670 FT-IR spectrometer. ${ }^{1} \mathrm{H}$ NMR and spectra were recorded on a Bruker $400 \mathrm{MHz}$ spectrometer at ambient temperature. Data are reported as follows: chemical shift in parts per million $(\delta, \mathrm{ppm})$ from an internal standard [tetramethylsilane (TMS) or deuterated chloroform $\left(\mathrm{CDCl}_{3}\right)$ ], multiplicity $(\mathrm{s}=$ singlet, $\mathrm{d}=$ doublet, $\mathrm{t}=$ triplet, $\mathrm{q}=$ quartet, and $\mathrm{m}=$ multiplet), integration, and coupling constant $(\mathrm{Hz}) .{ }^{13} \mathrm{C}$ NMR and spectra were recorded on a Bruker $400 \mathrm{MHz}$ spectrometer at ambient temperature. Chemical shifts are reported in ppm from $\mathrm{CDCl}_{3}$ taken as $77.0 \mathrm{ppm}$. Mass spectra were obtained on Micromass, Inc. (Waters) Autospec high resolution mass spectrometer using an ESI or EI method. 


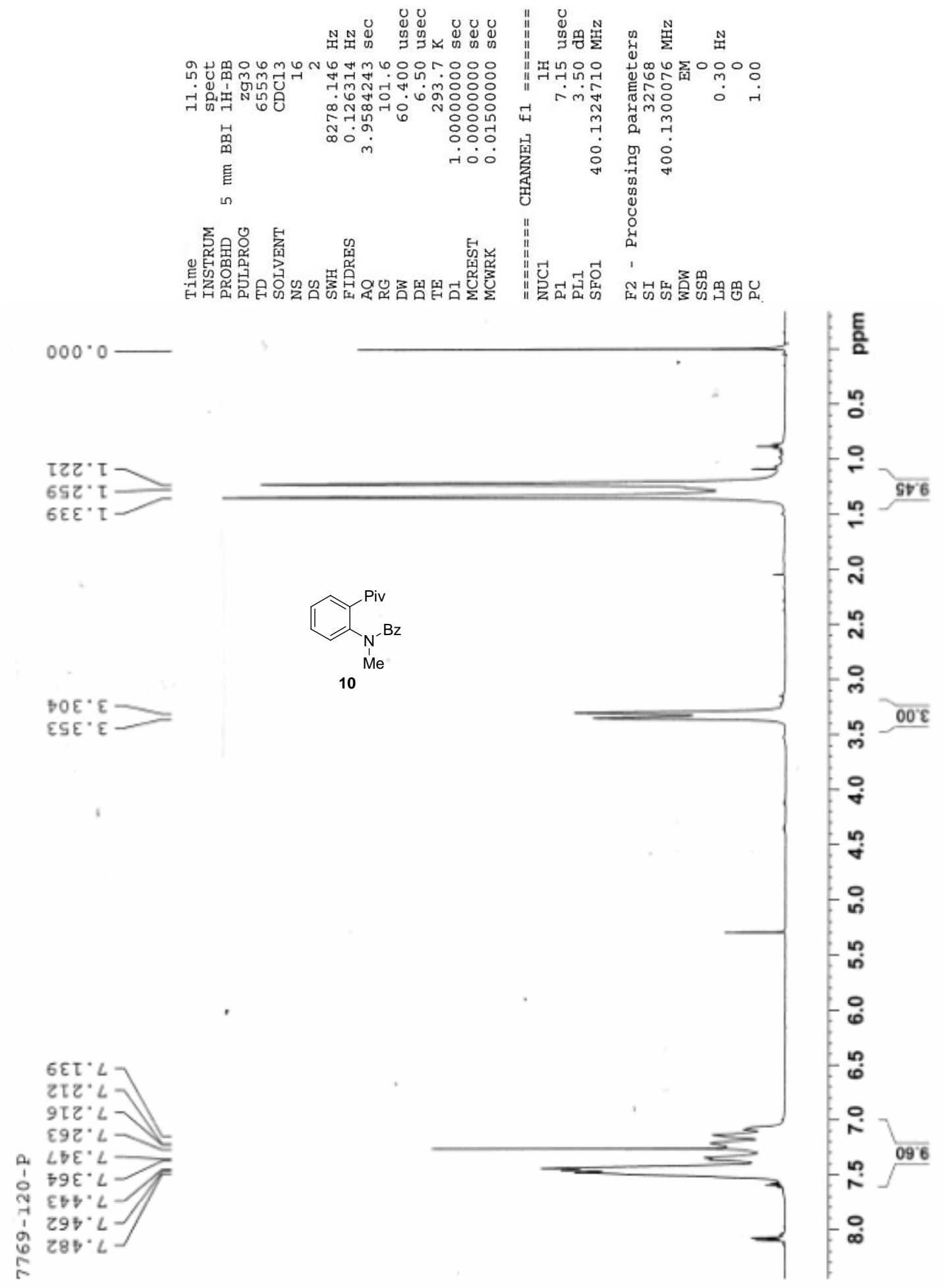



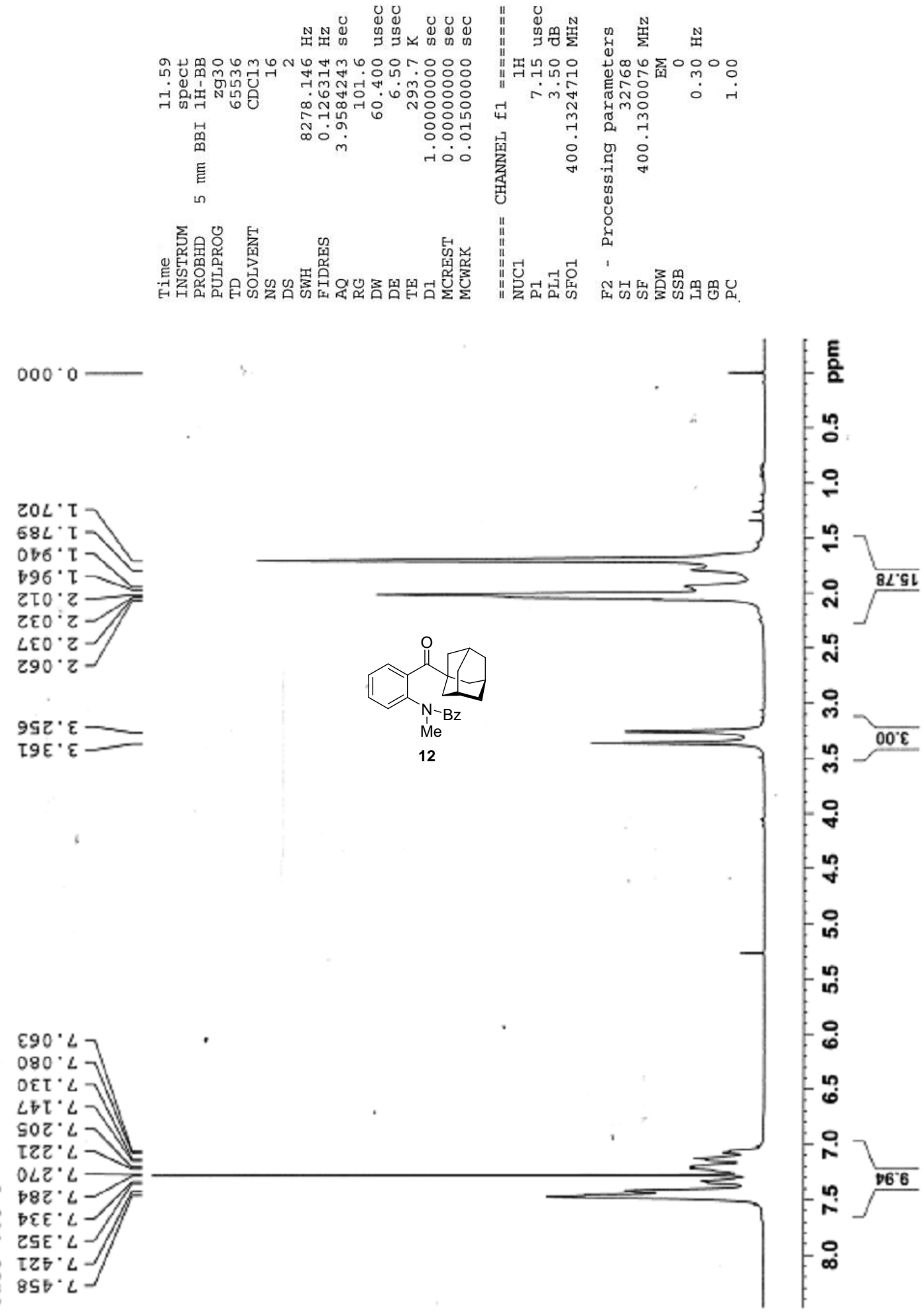

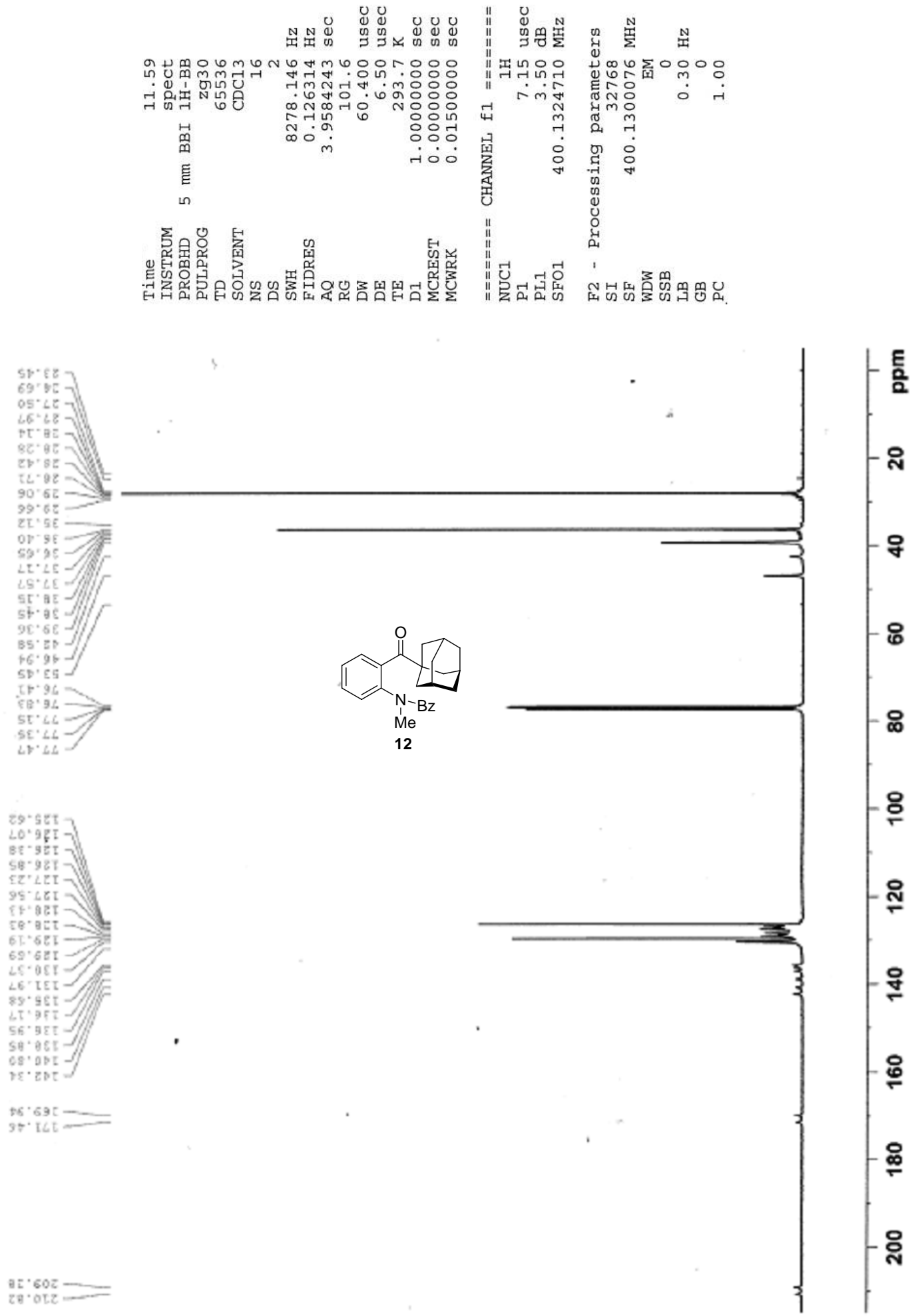

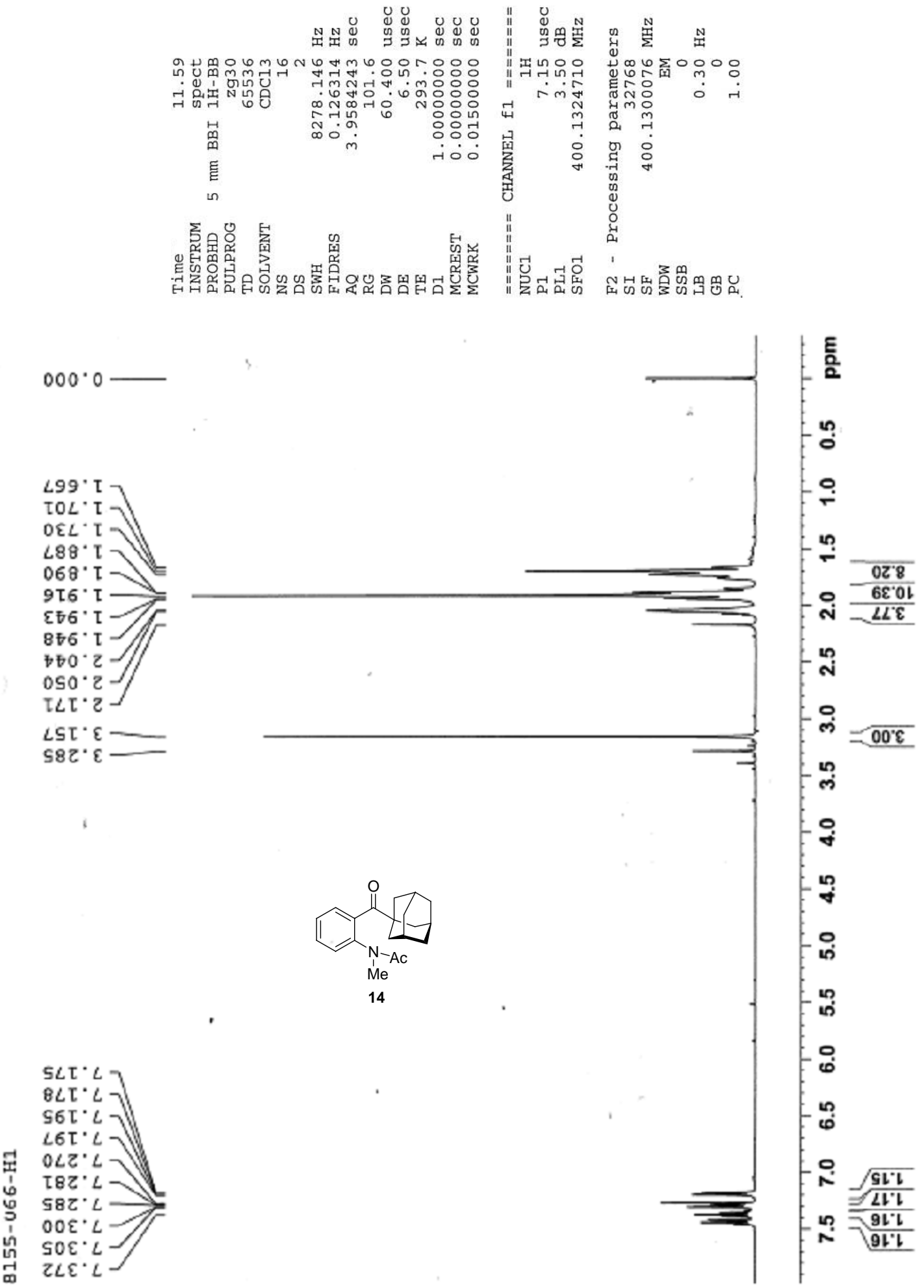

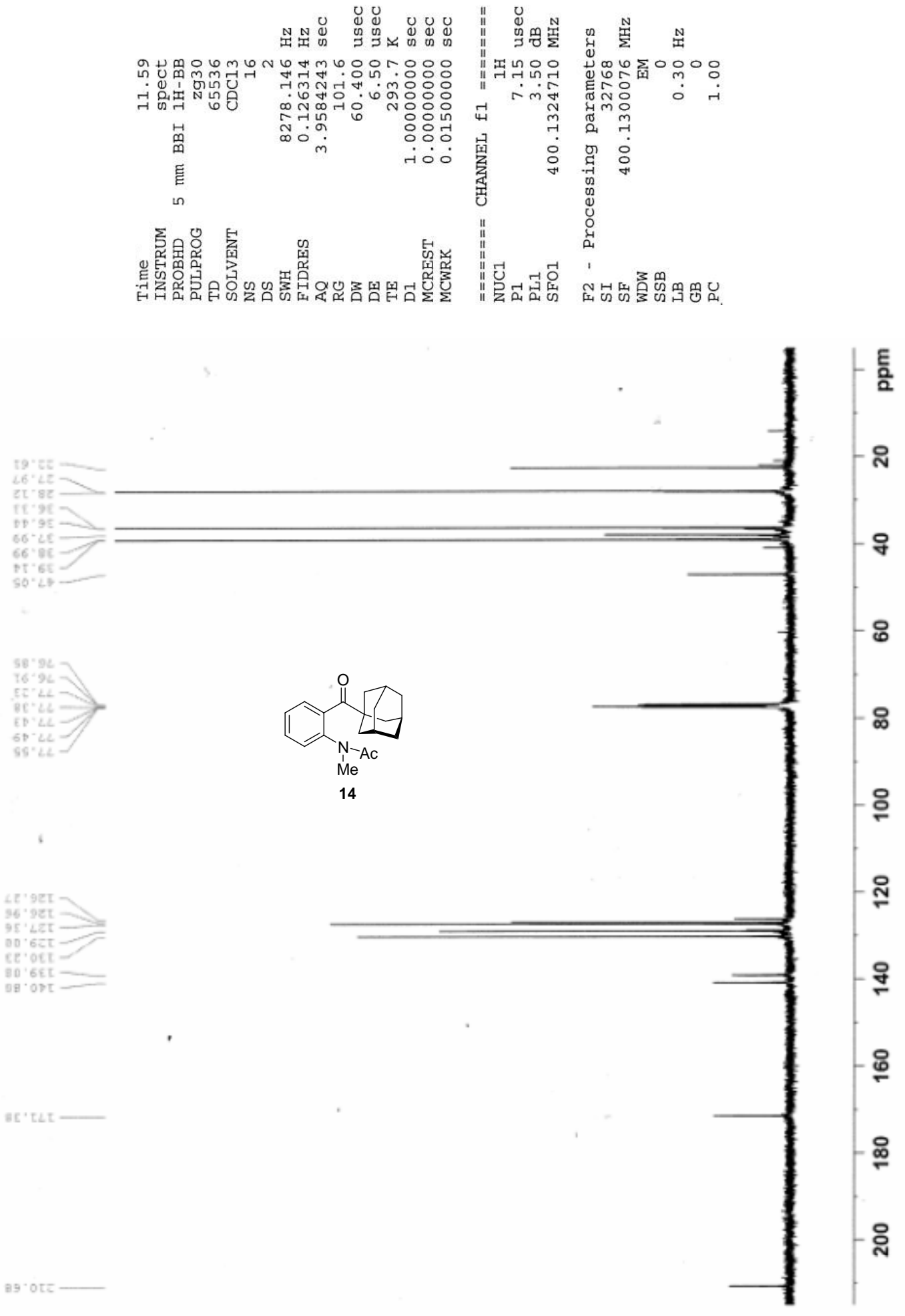

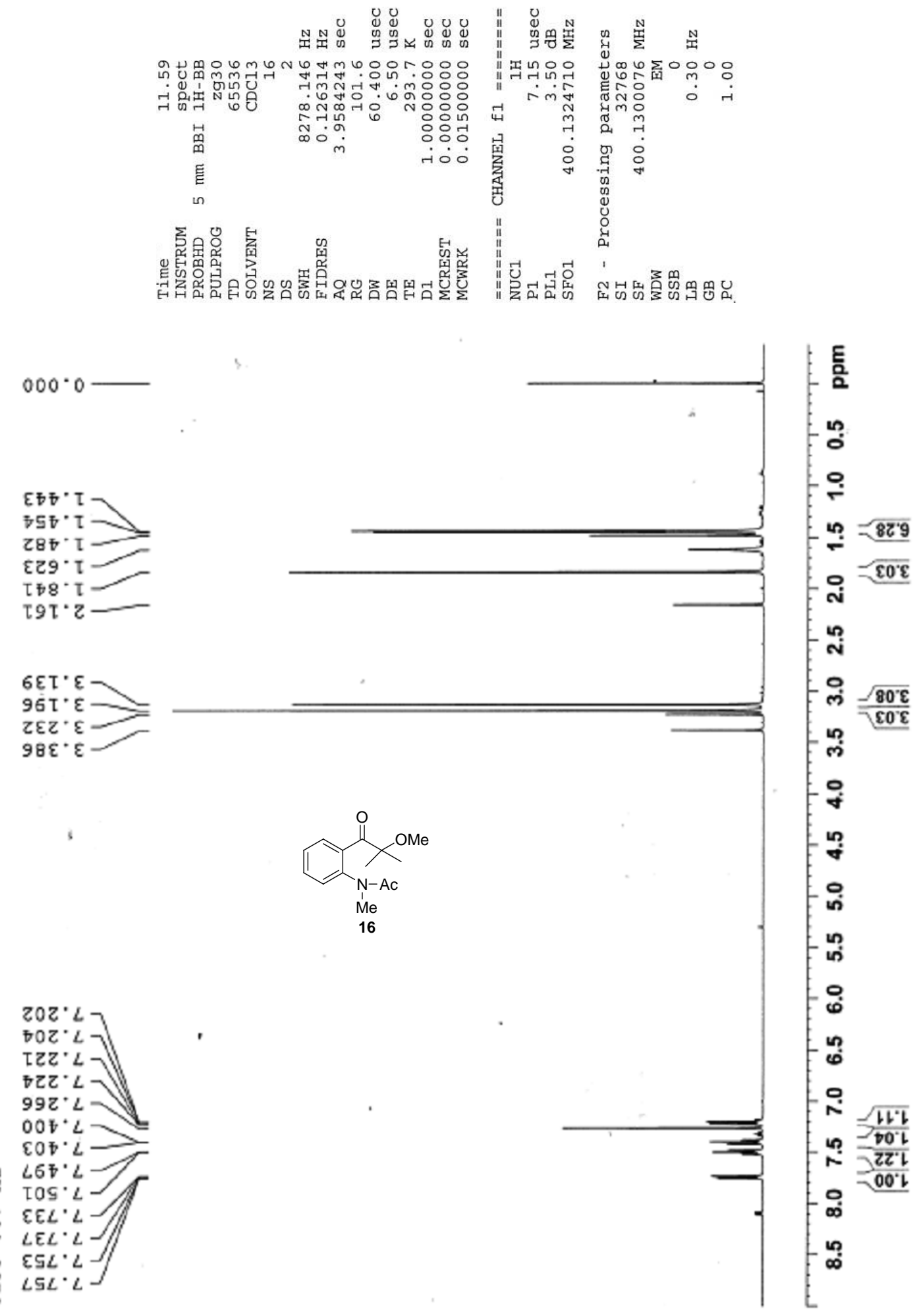

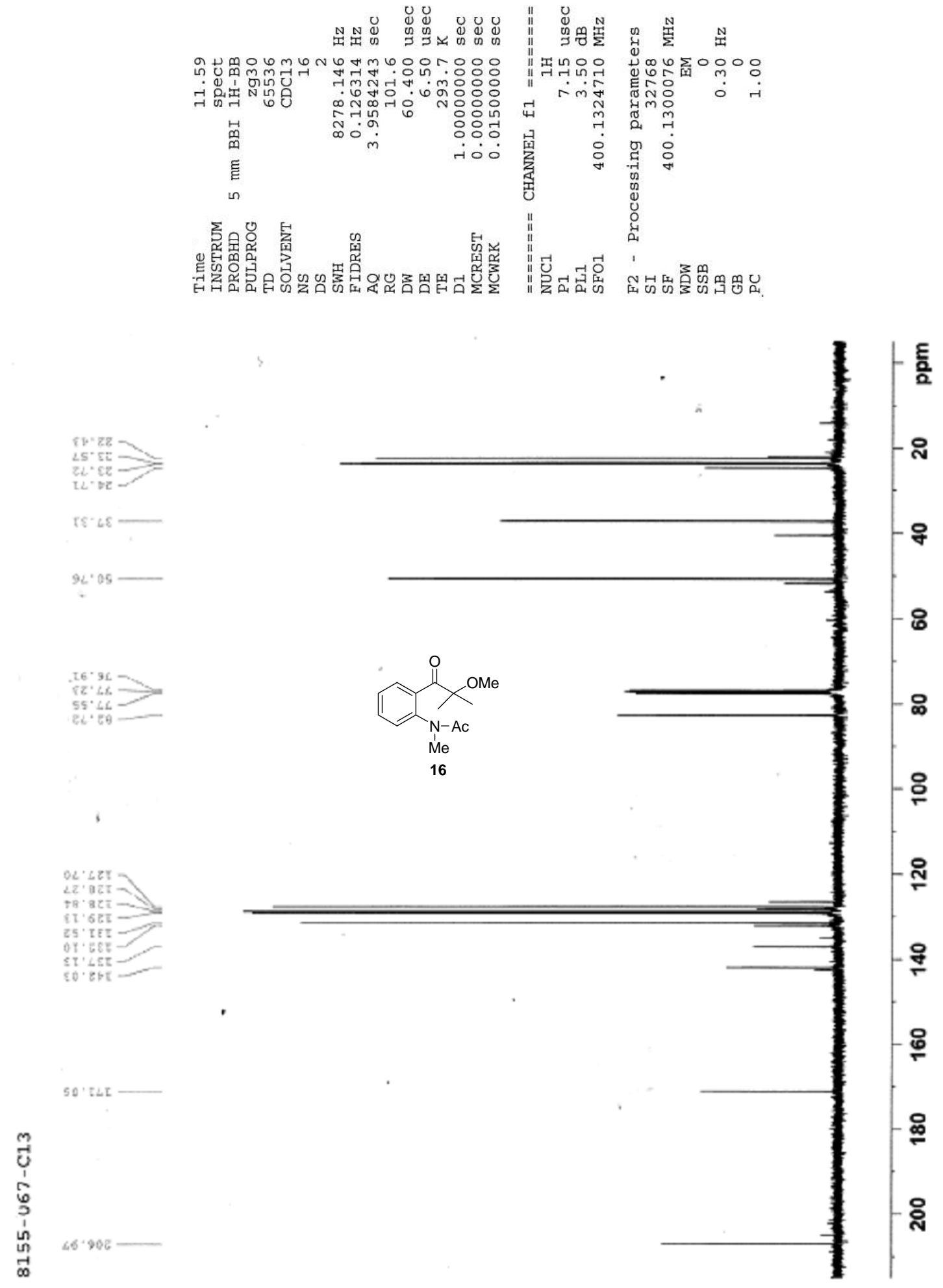

กิ
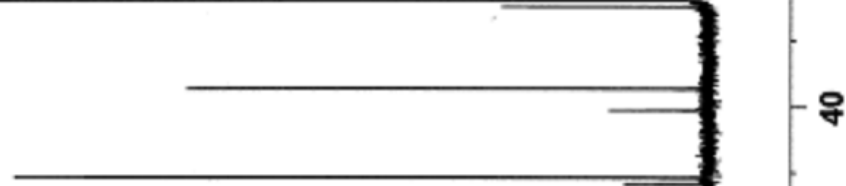

8 

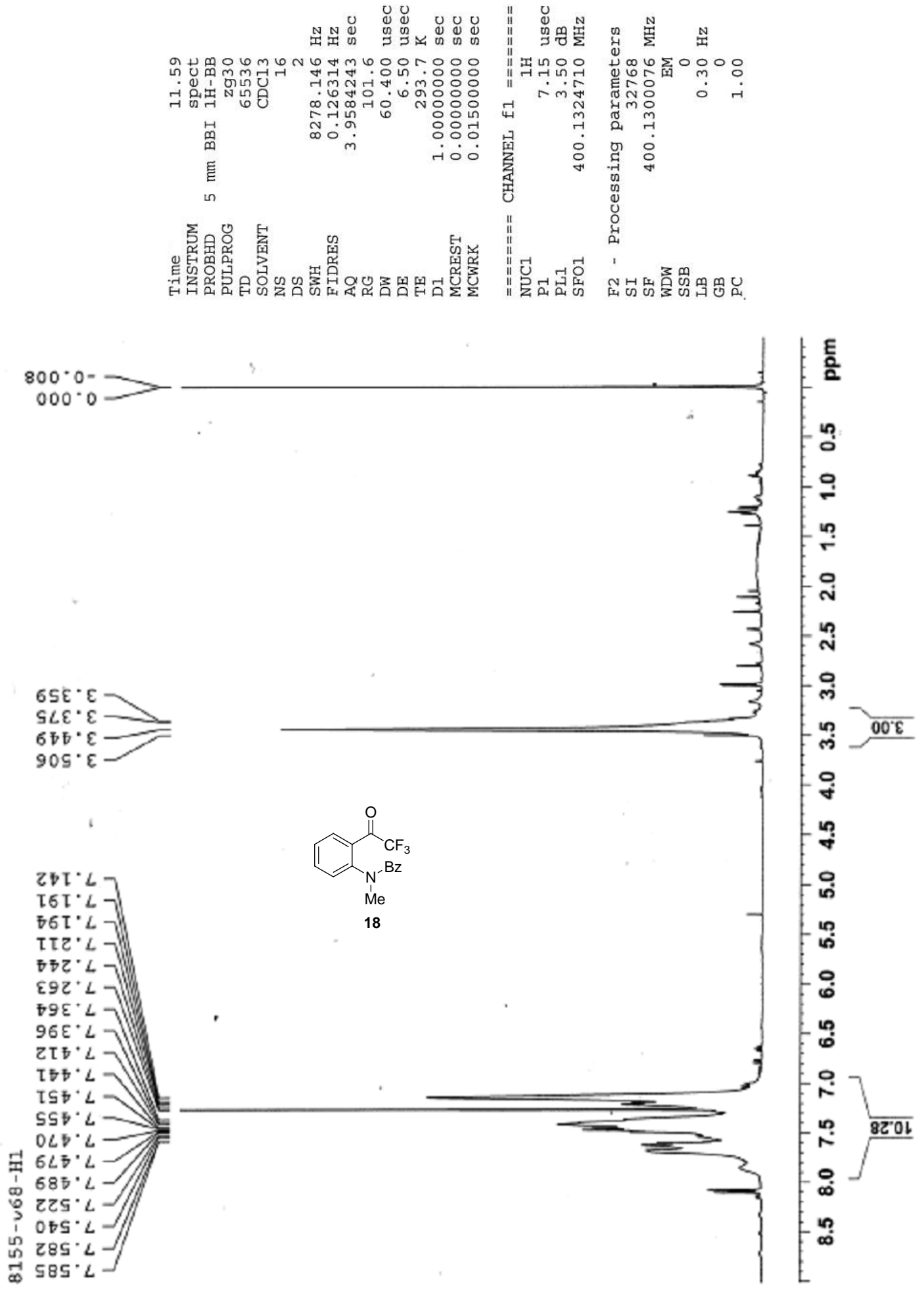

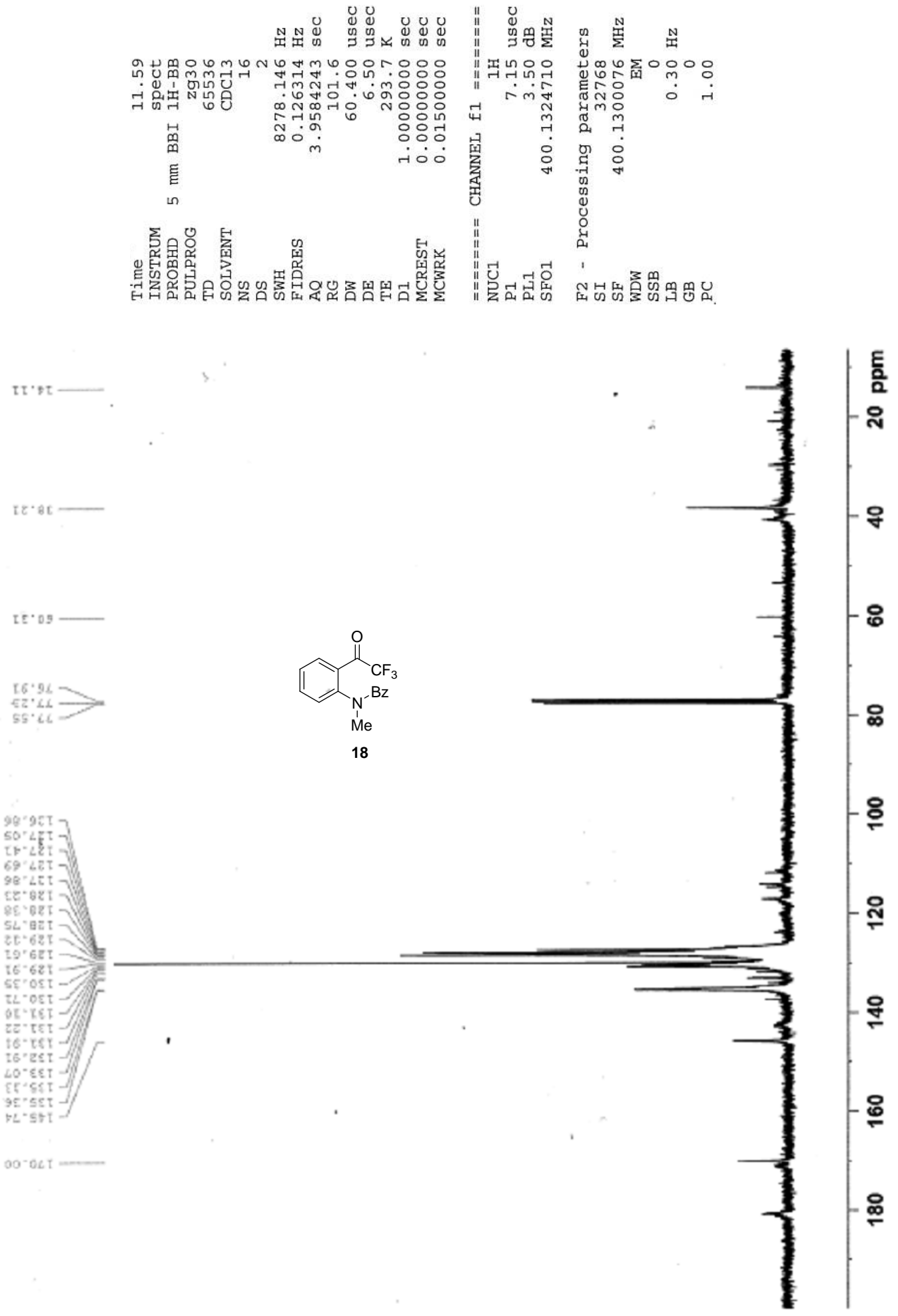

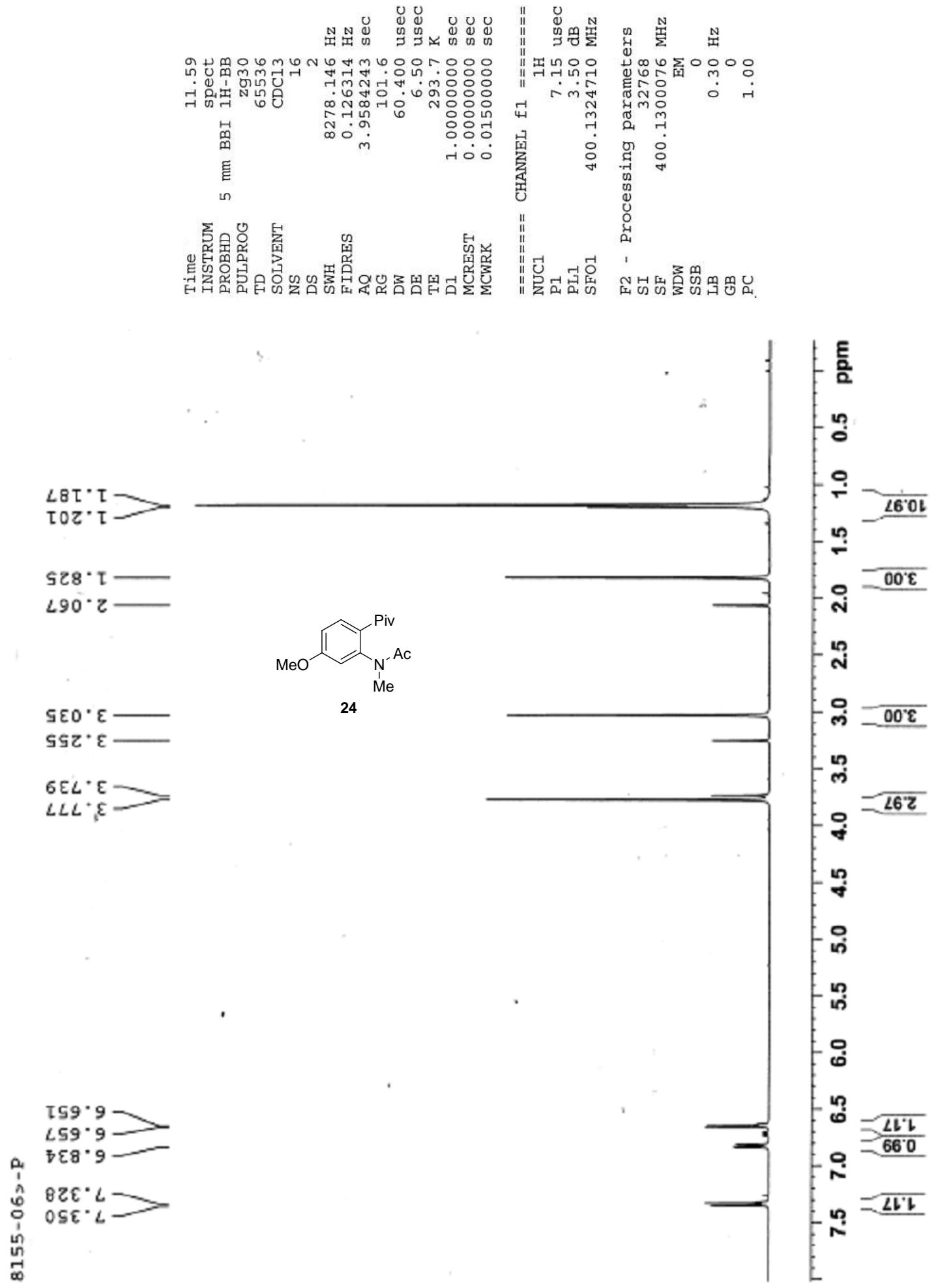

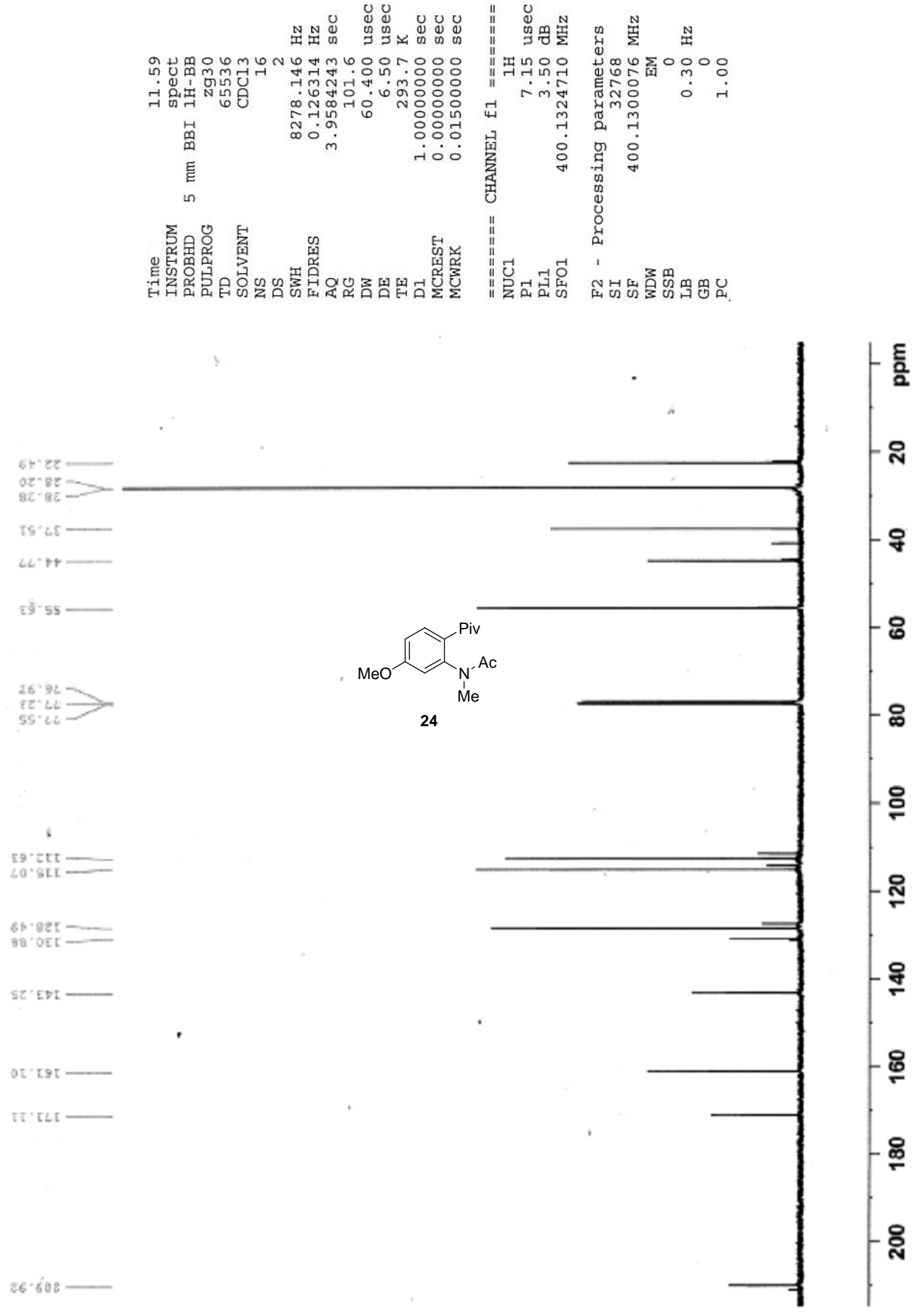

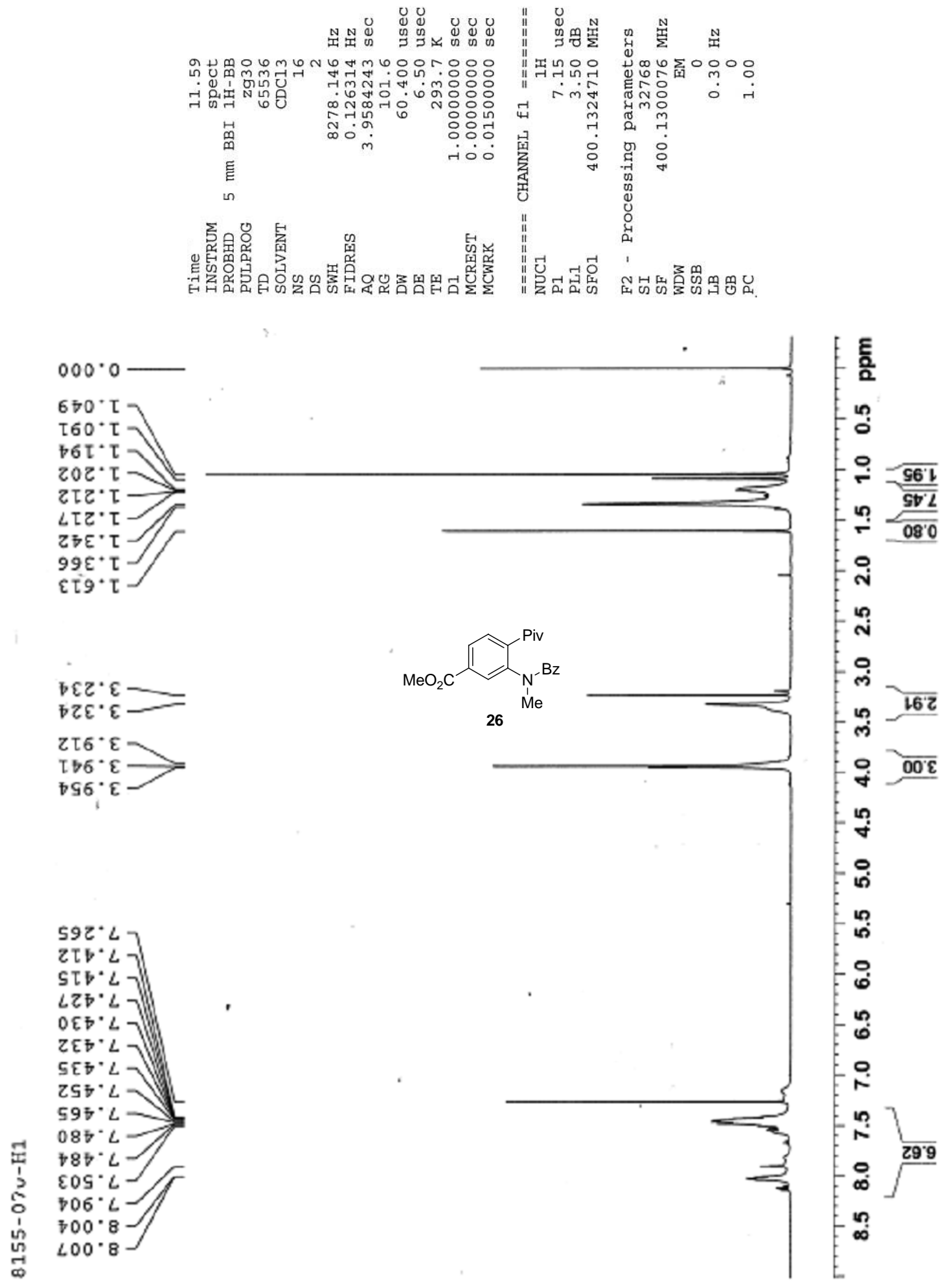

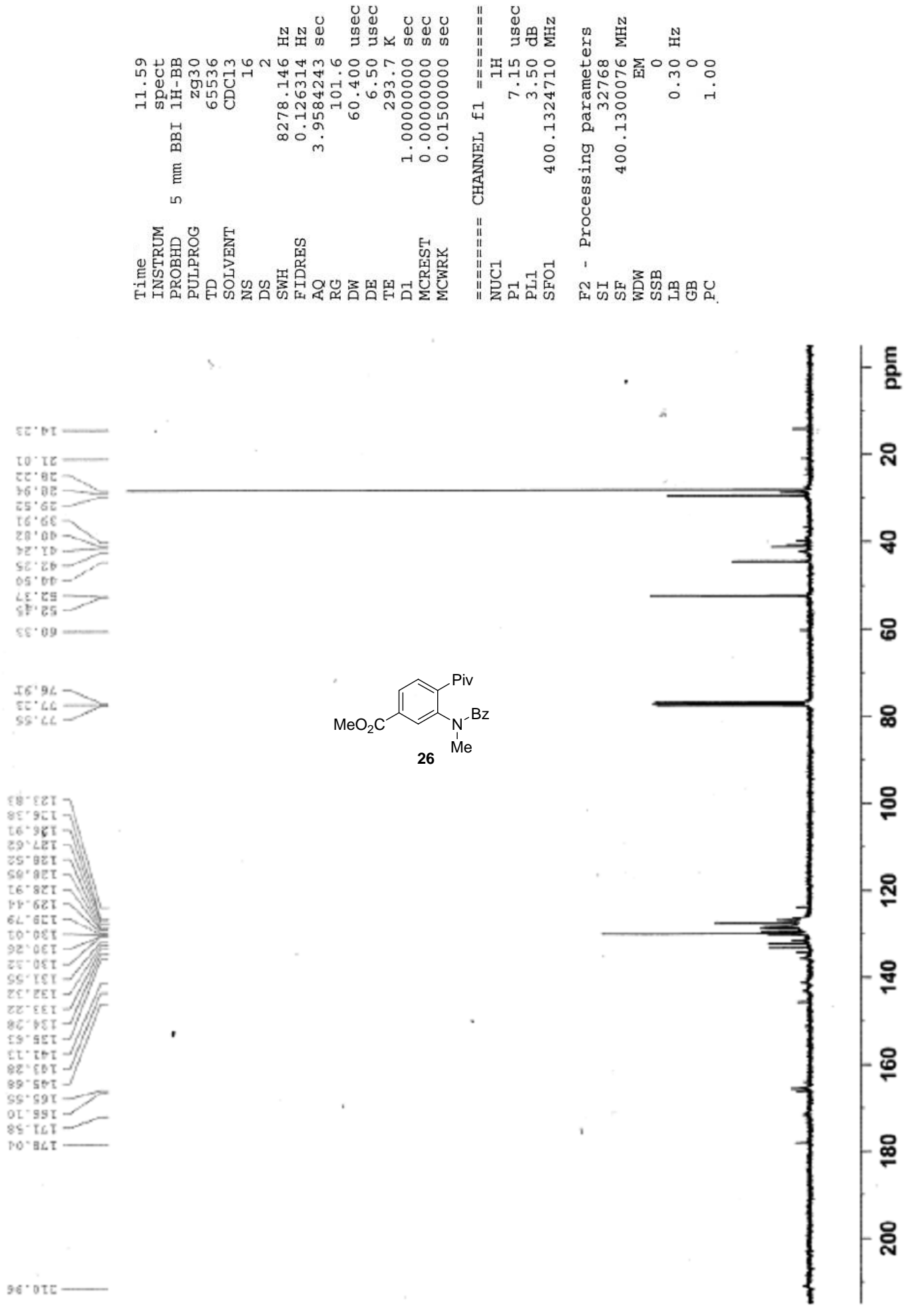

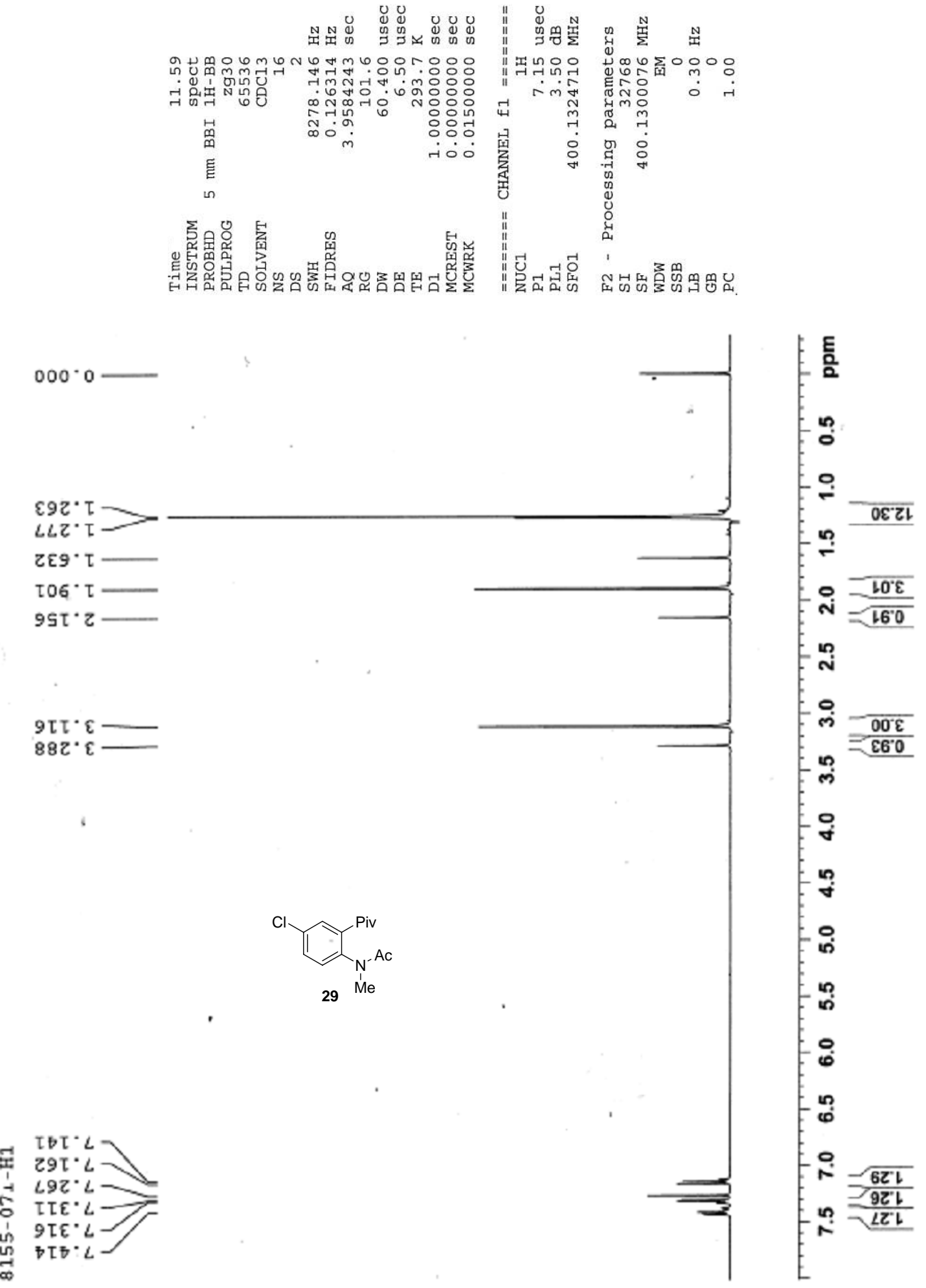

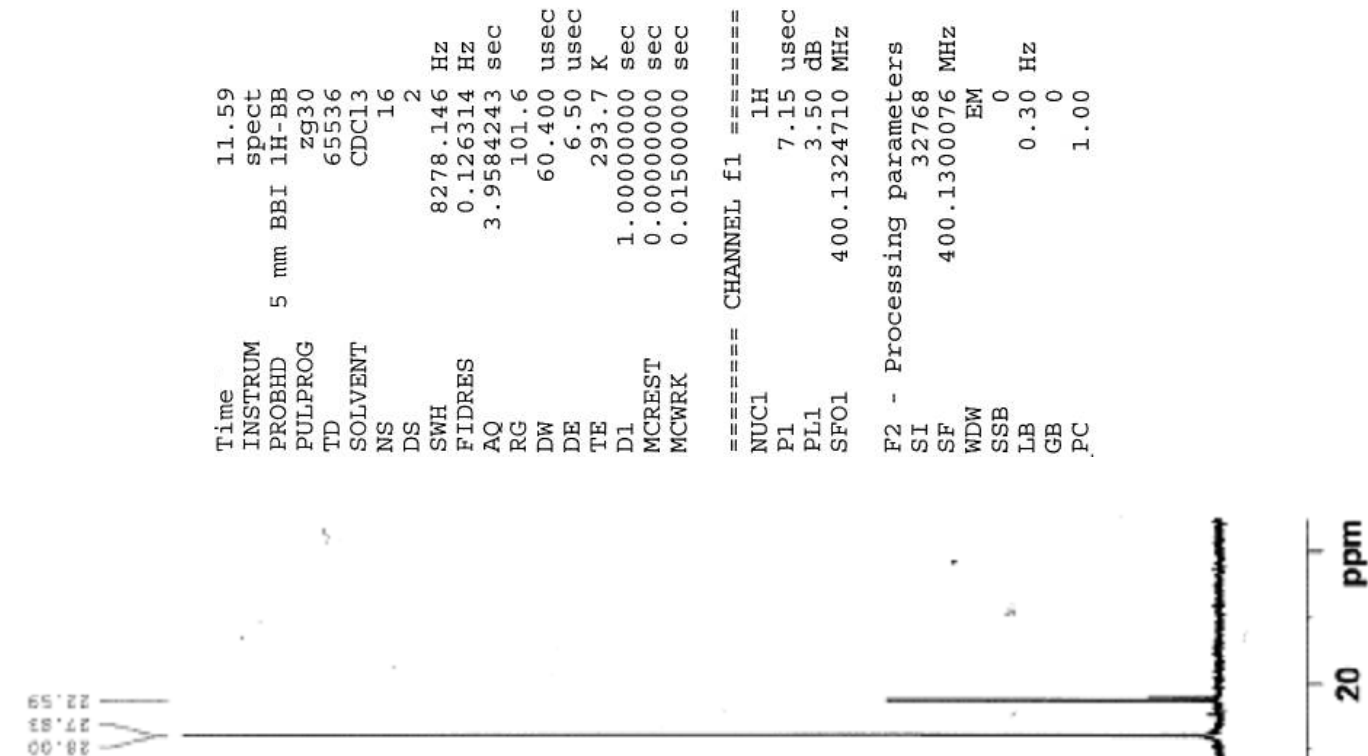

56.65

26.050
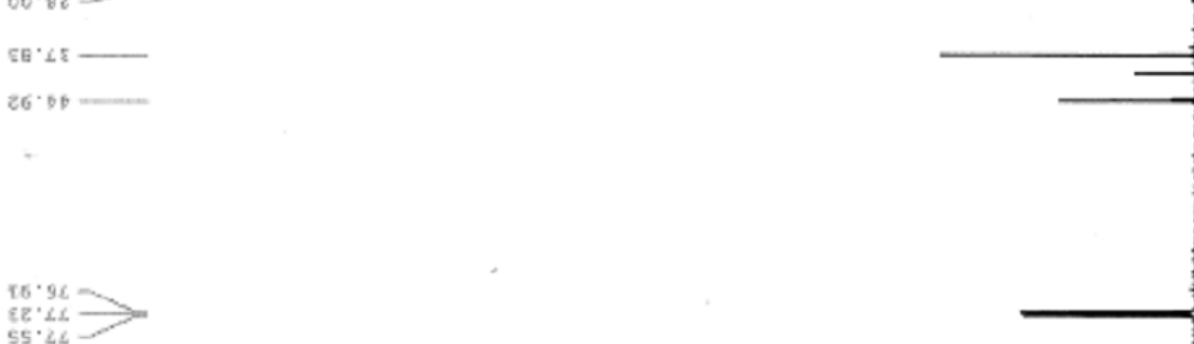

$96 \cdot 927$

$90^{\circ} 061$

D. DET

$39 \cdot 05 T-$

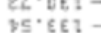

$25.857-2$

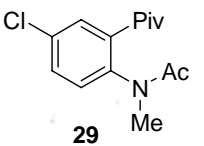

틍

क्ष

Me

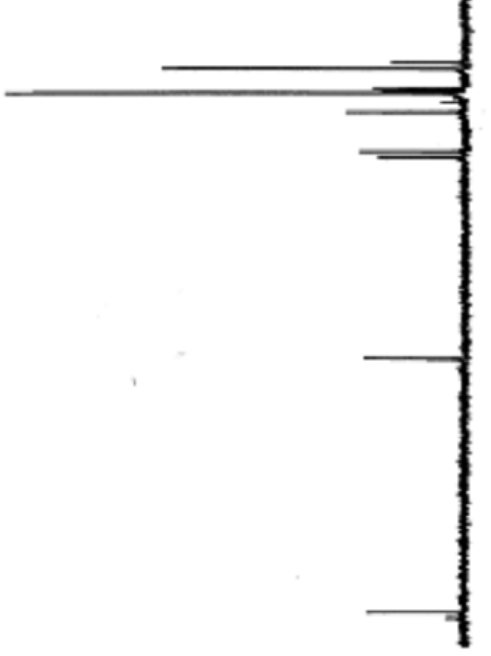

- ฐิ

운

:

$9 \tau \cdot T L \tau$

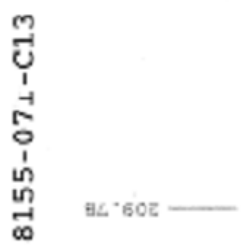

-

오 

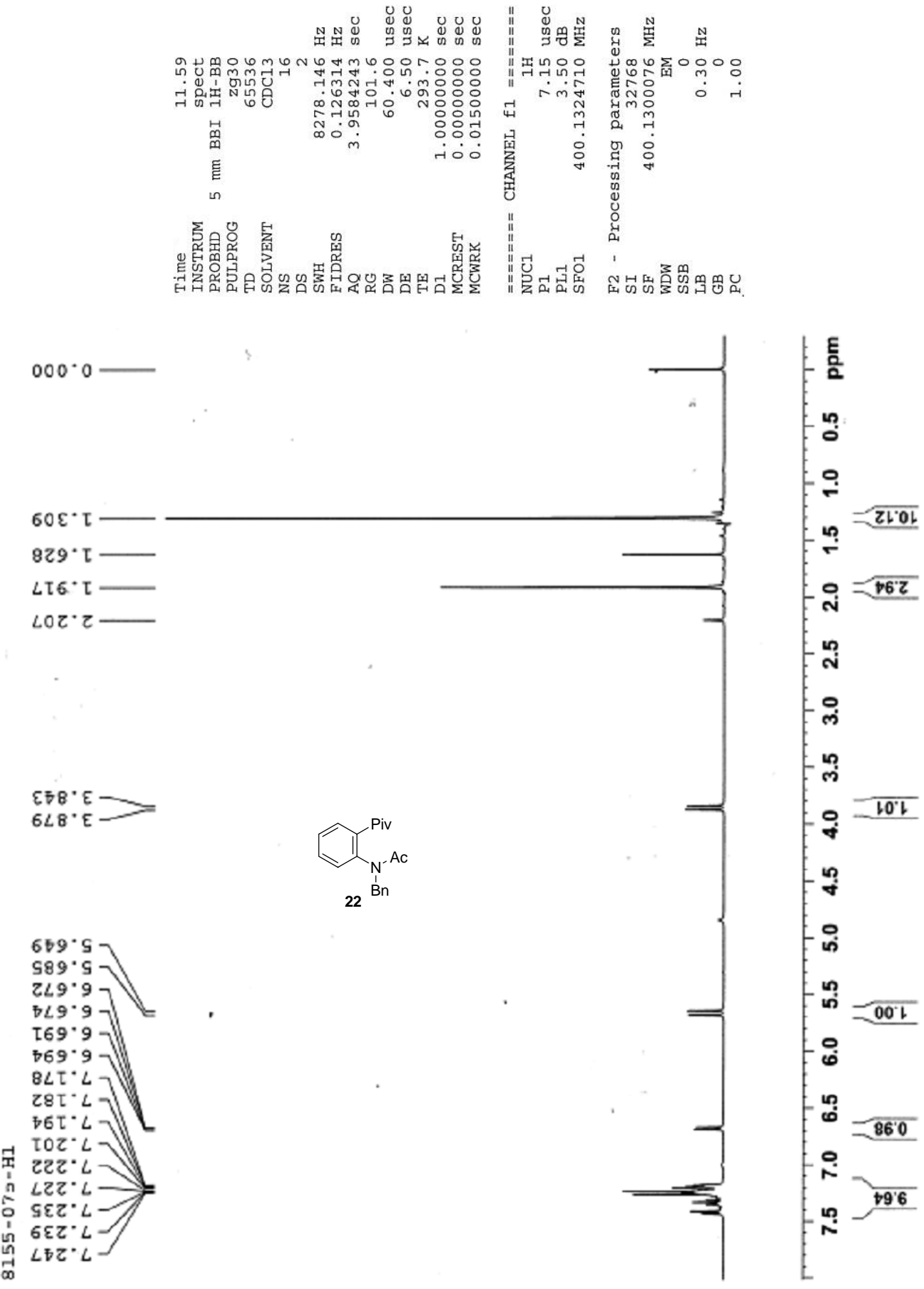

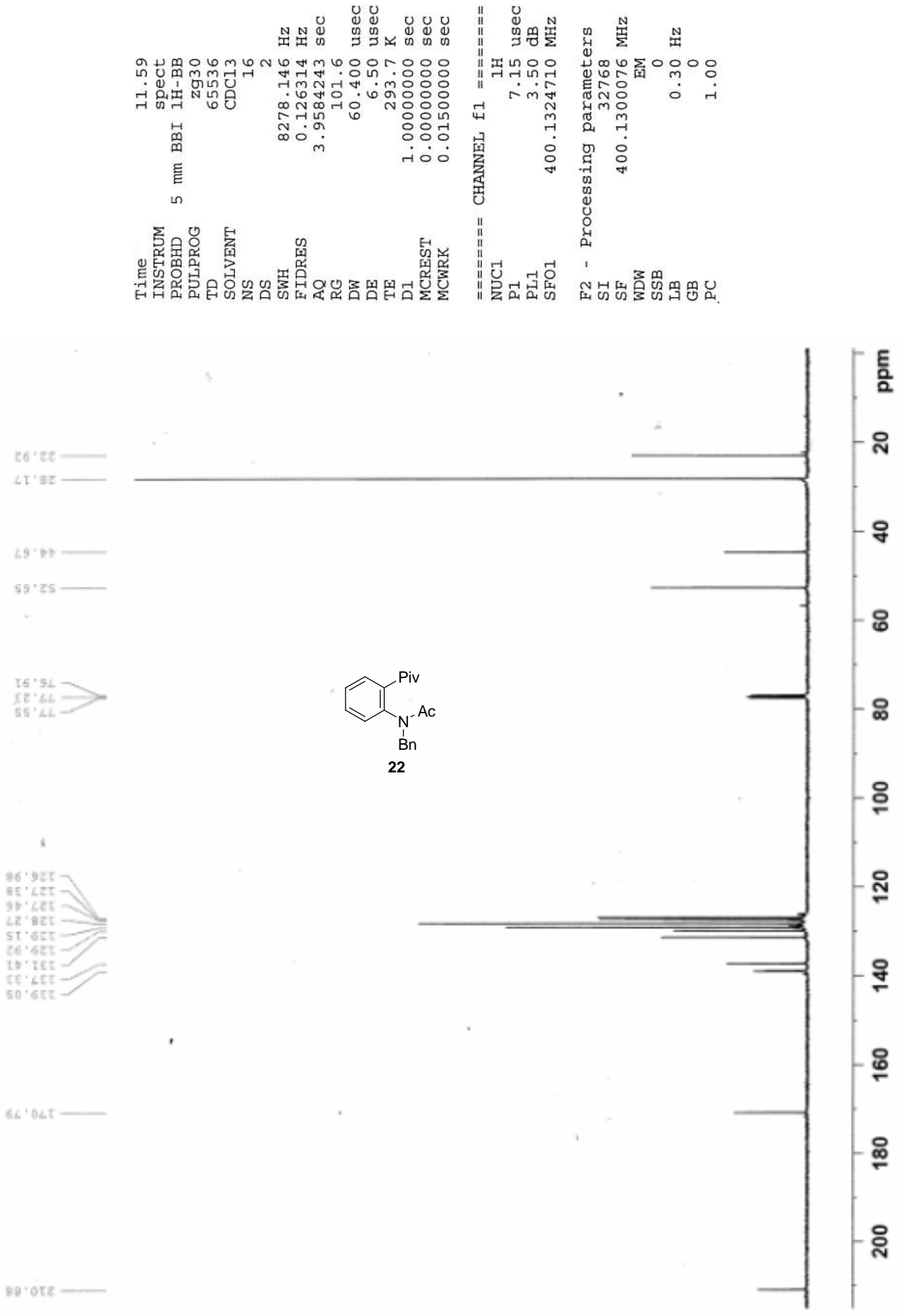

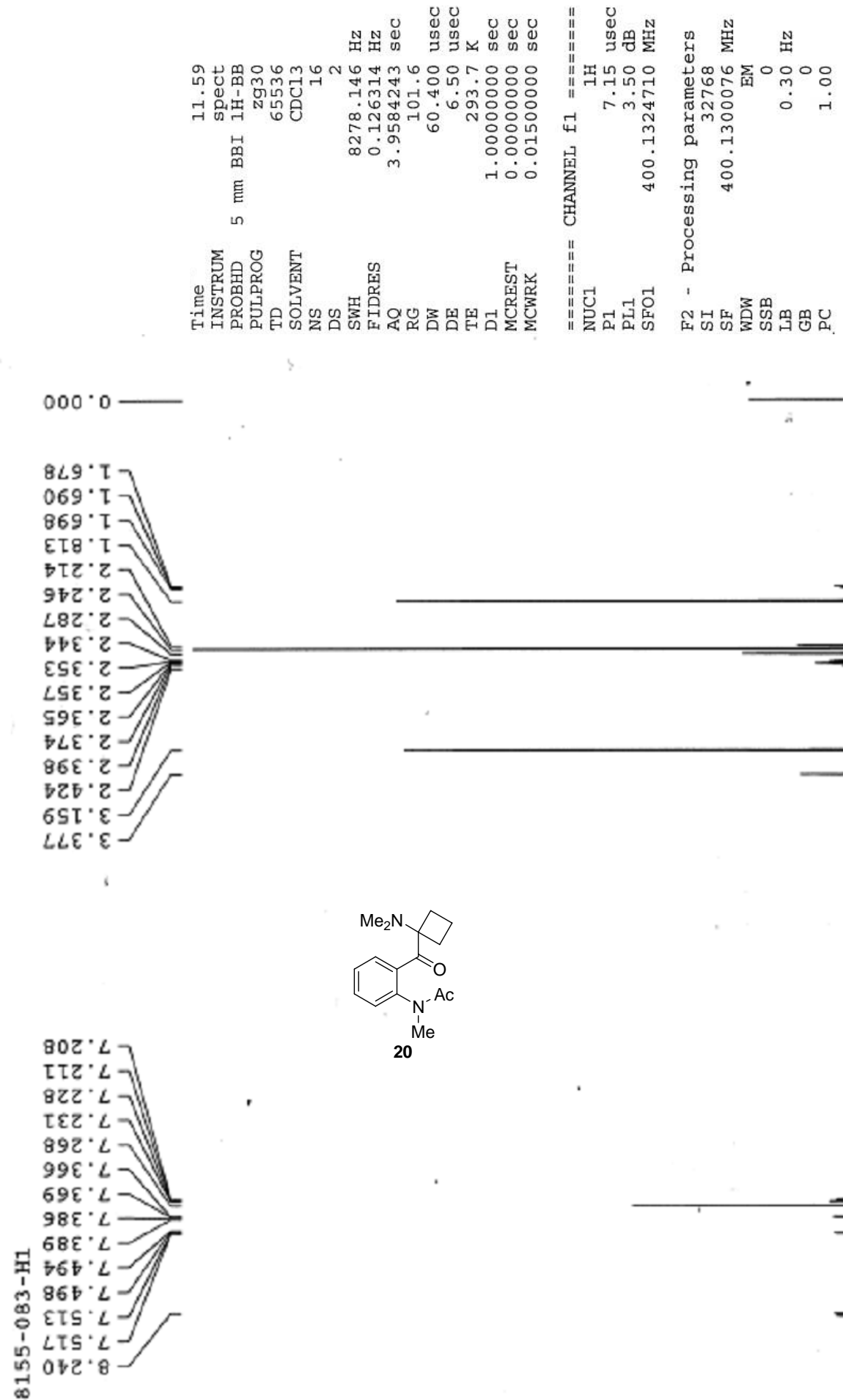

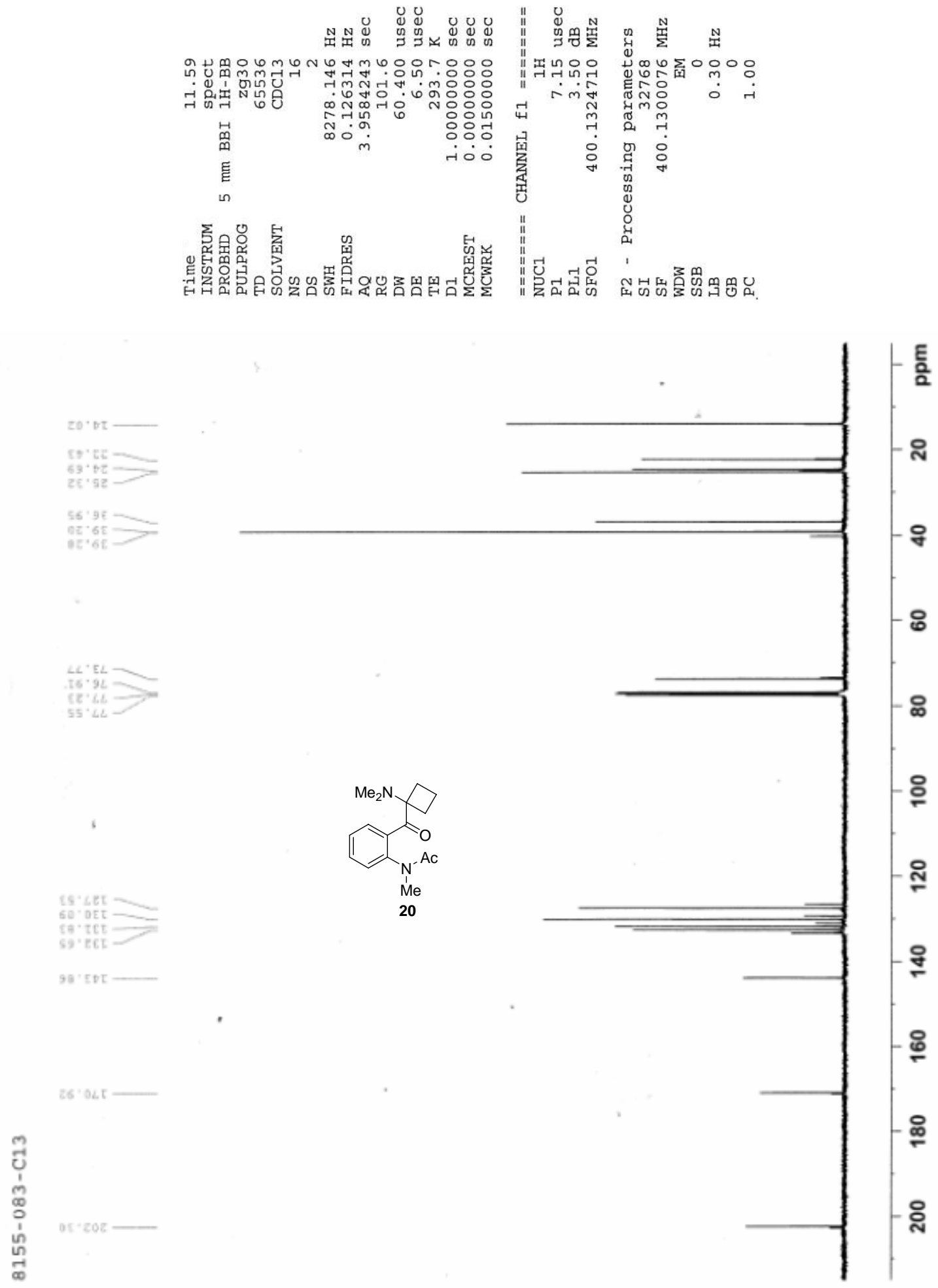

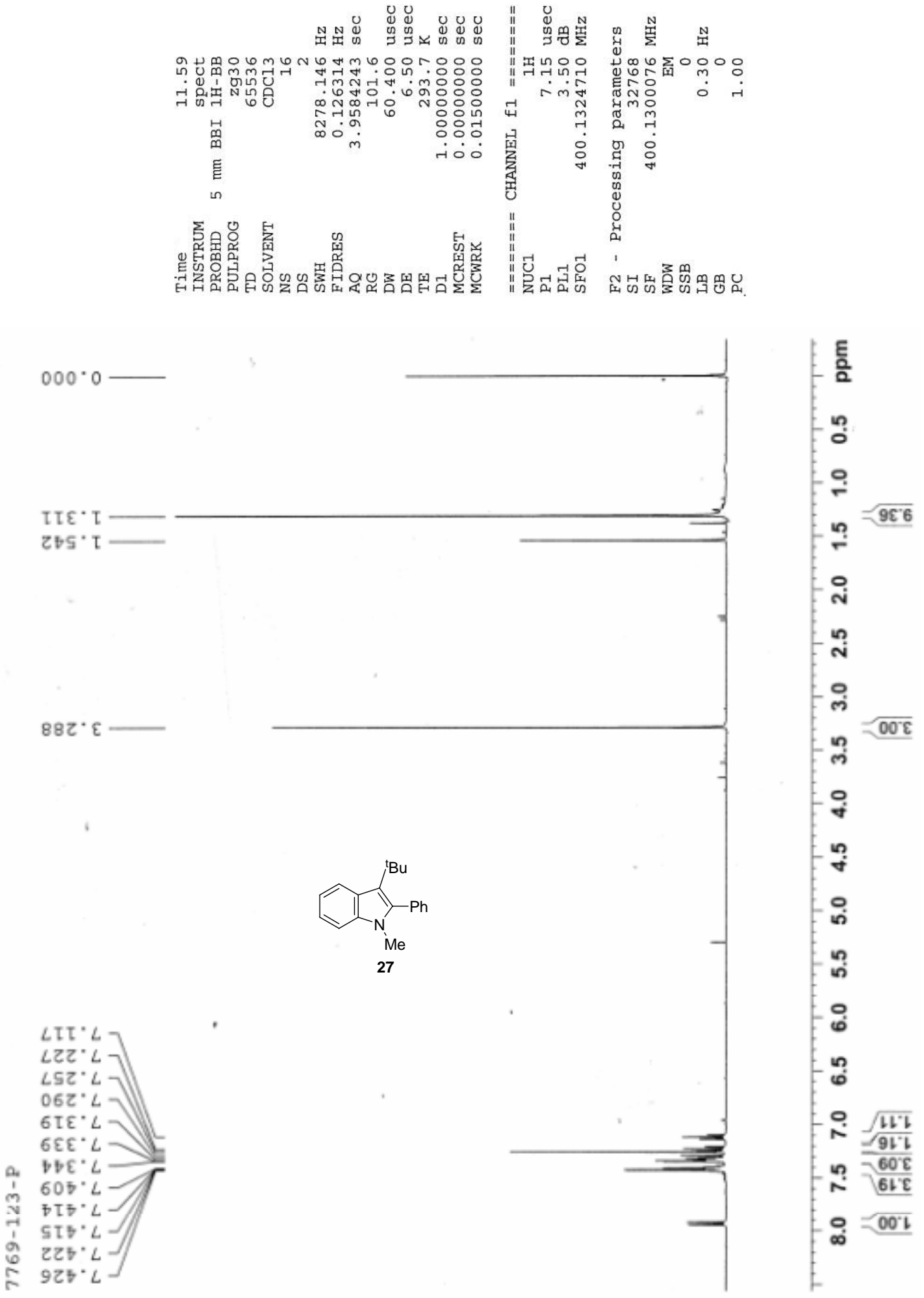

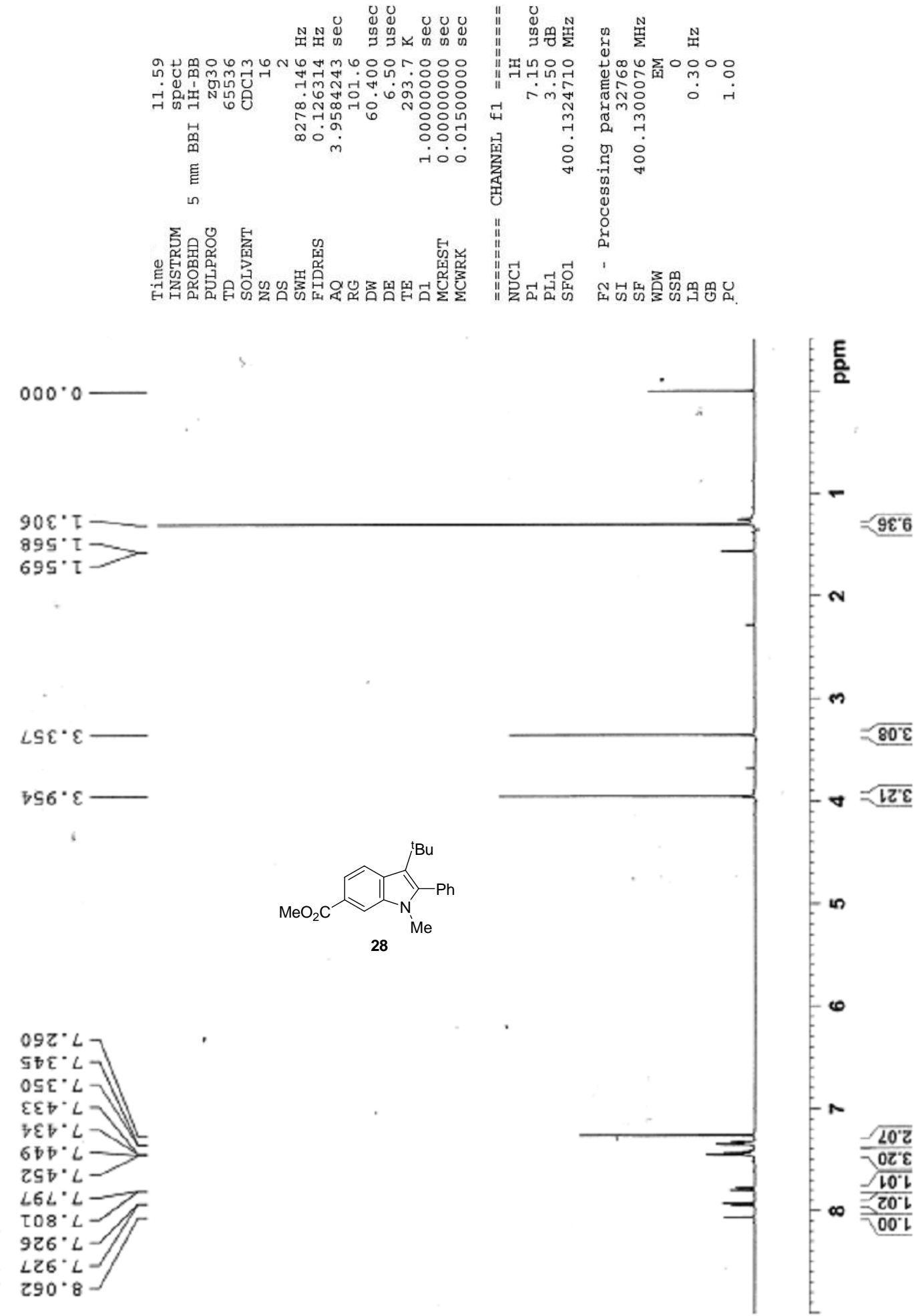

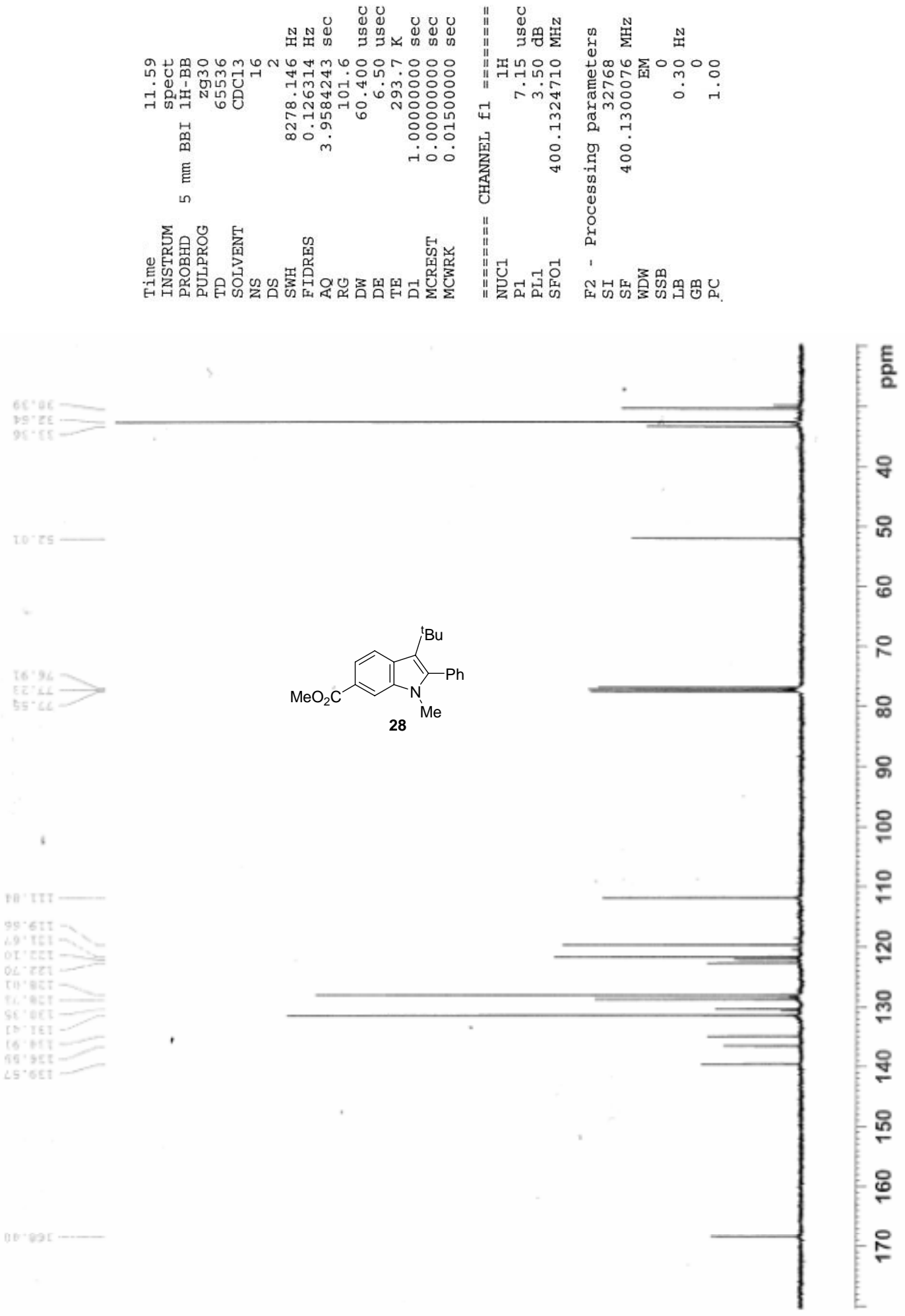

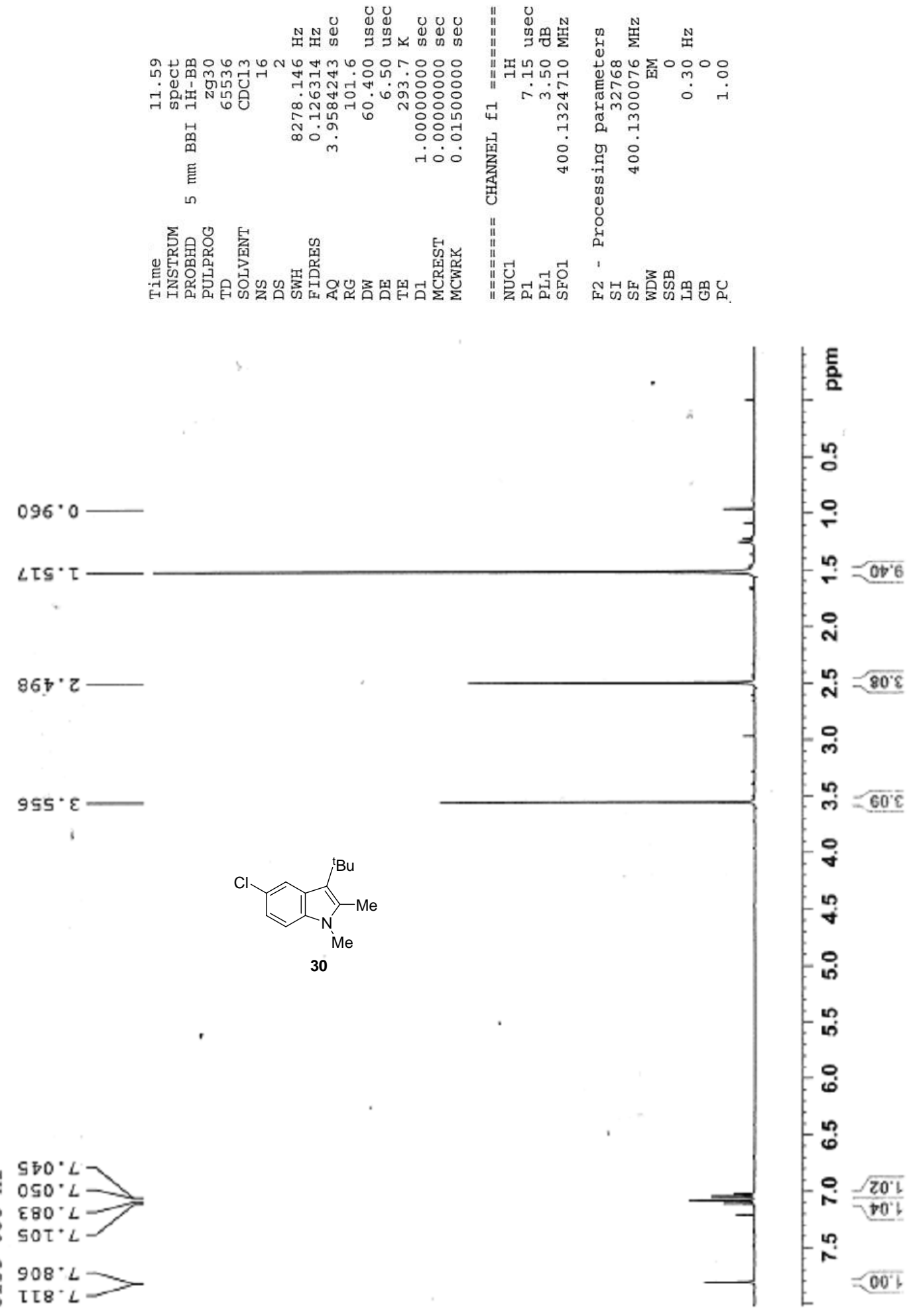

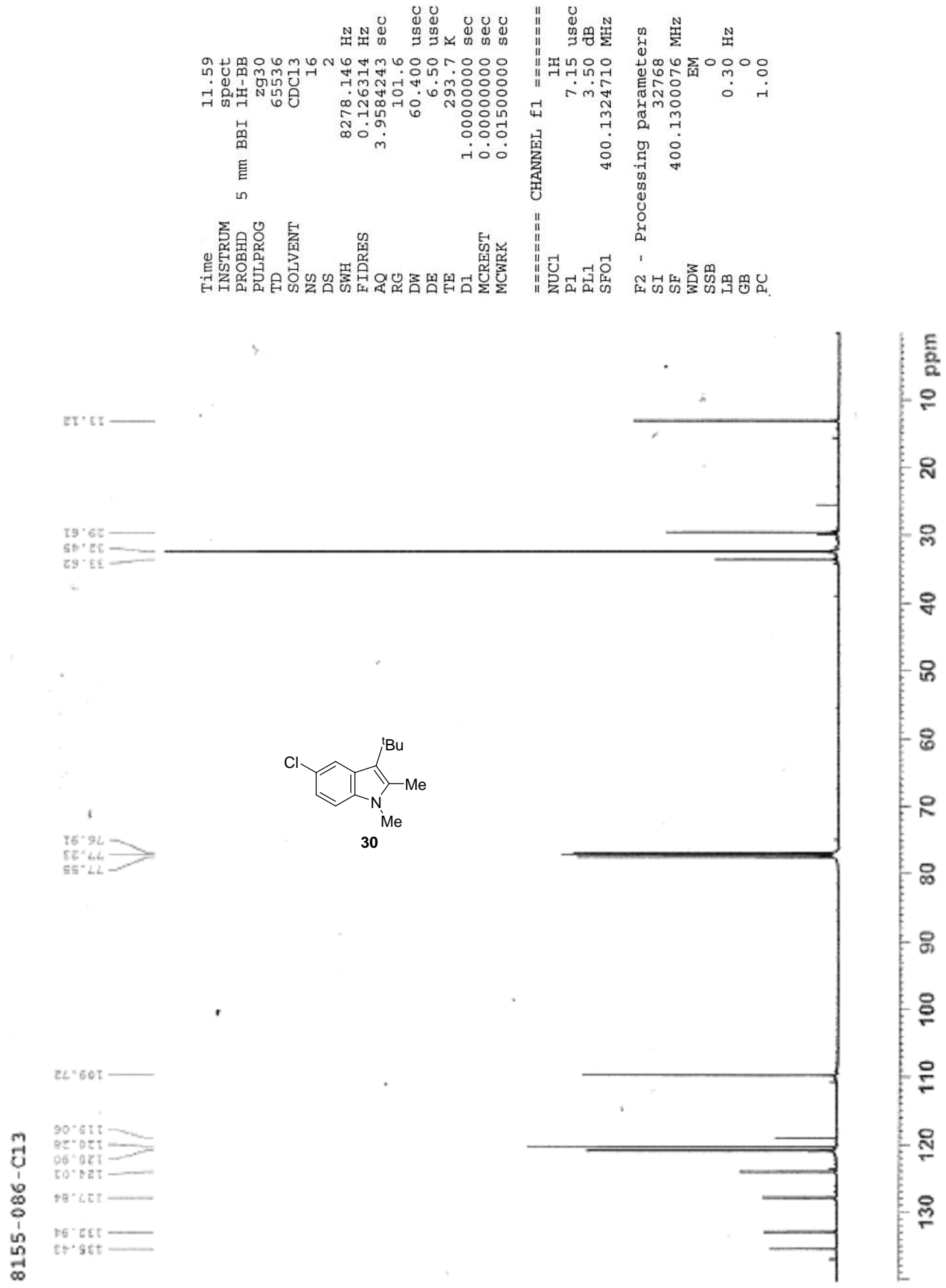

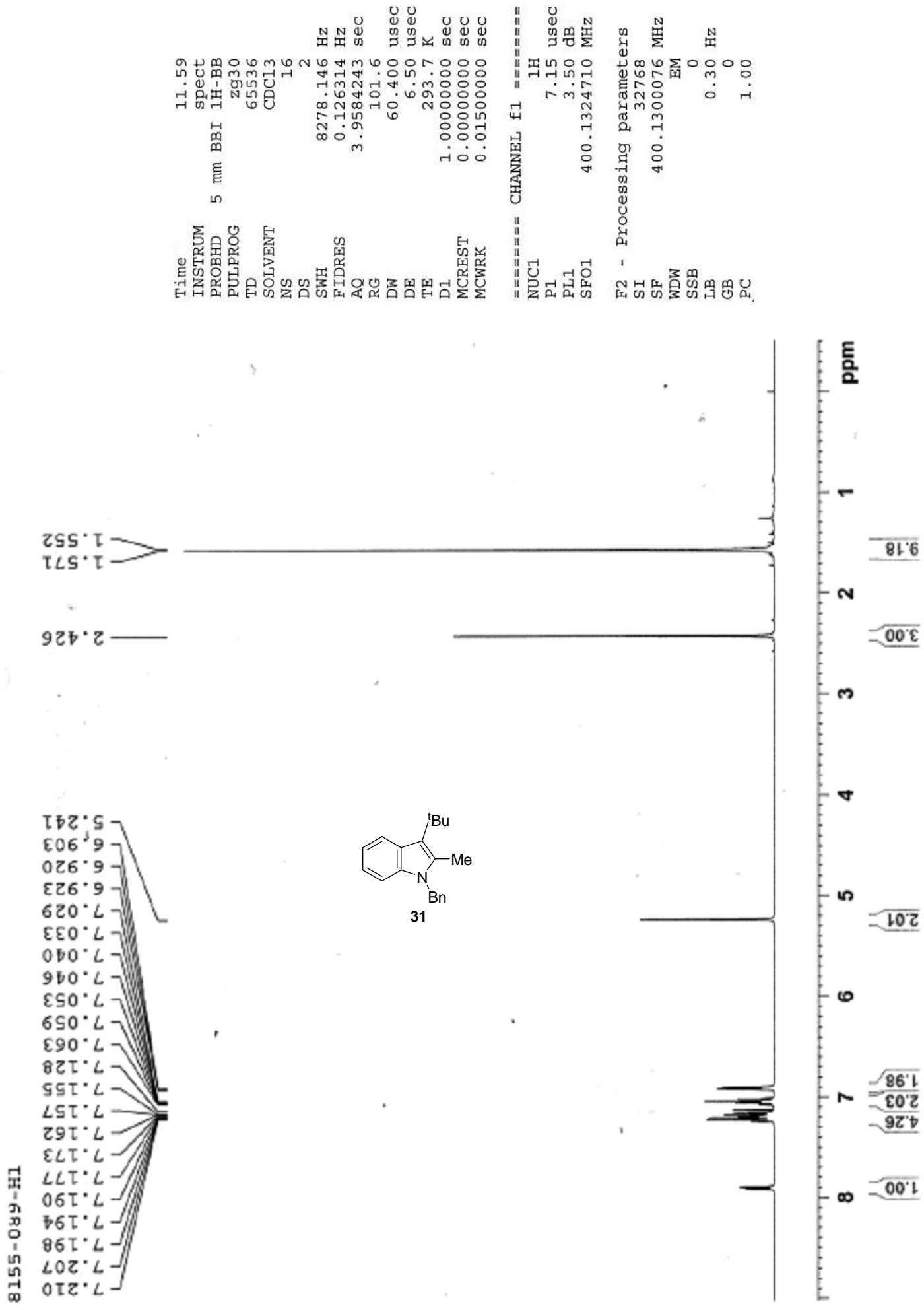


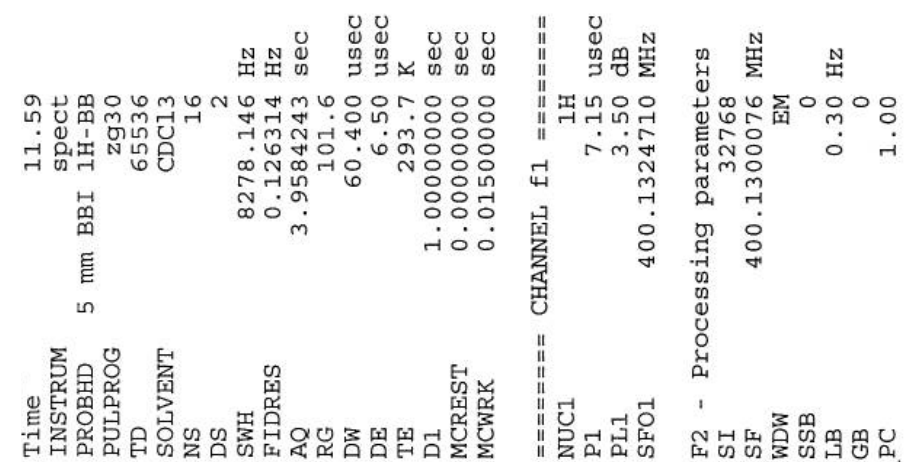

$96 \cdot 2 \pi+\cdots$

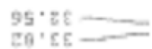

$8 z \cdot 96$

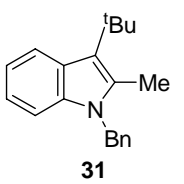

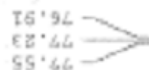

,
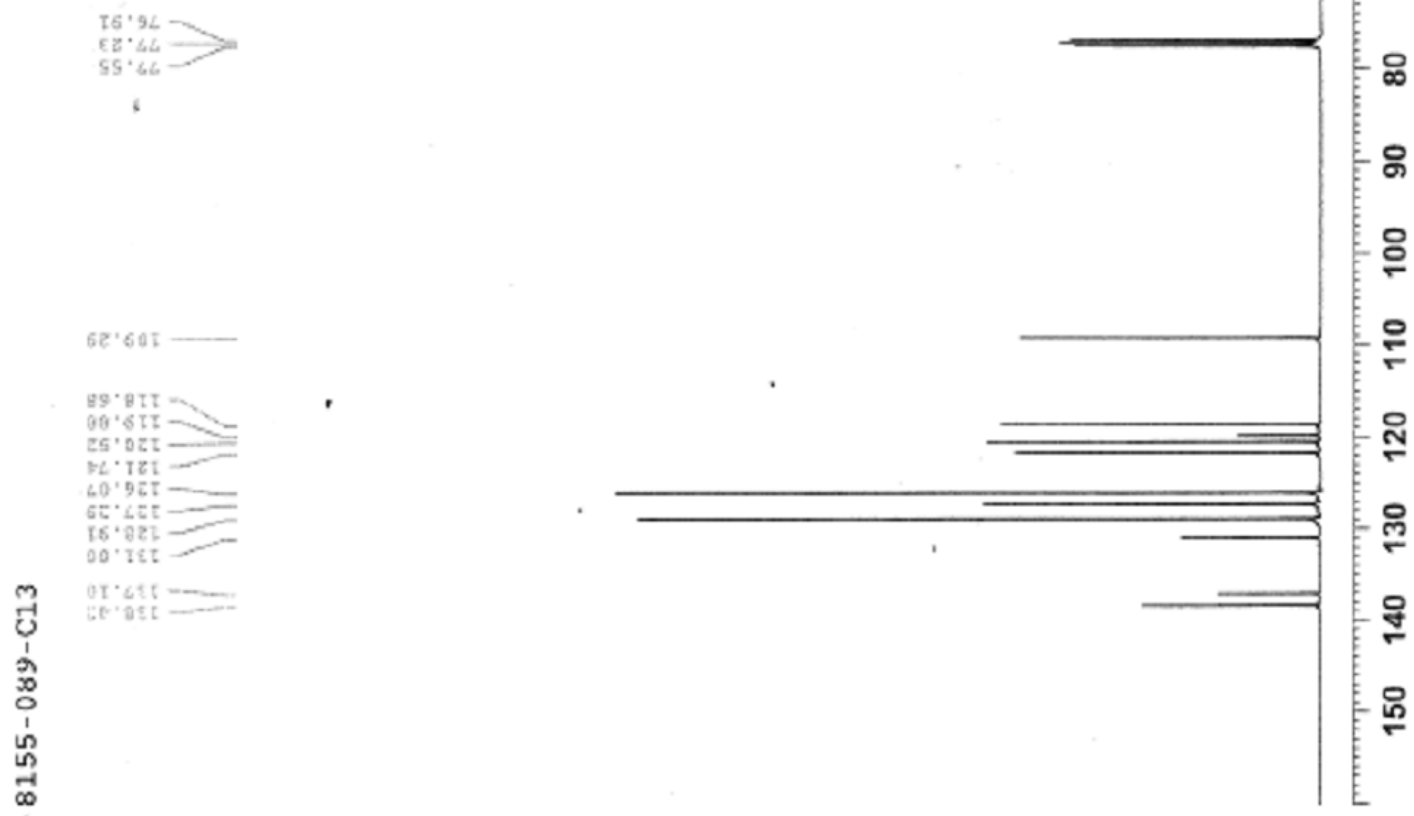

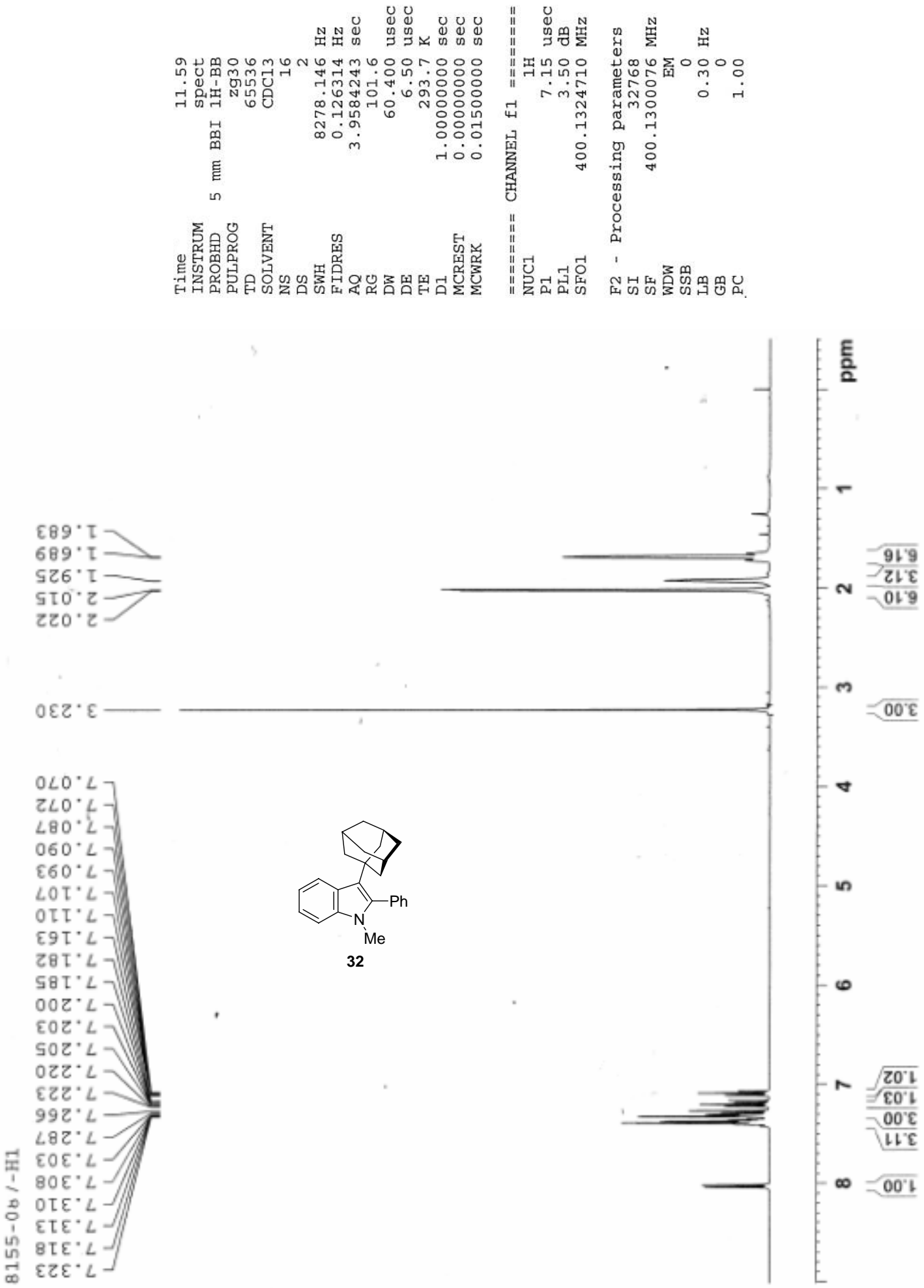

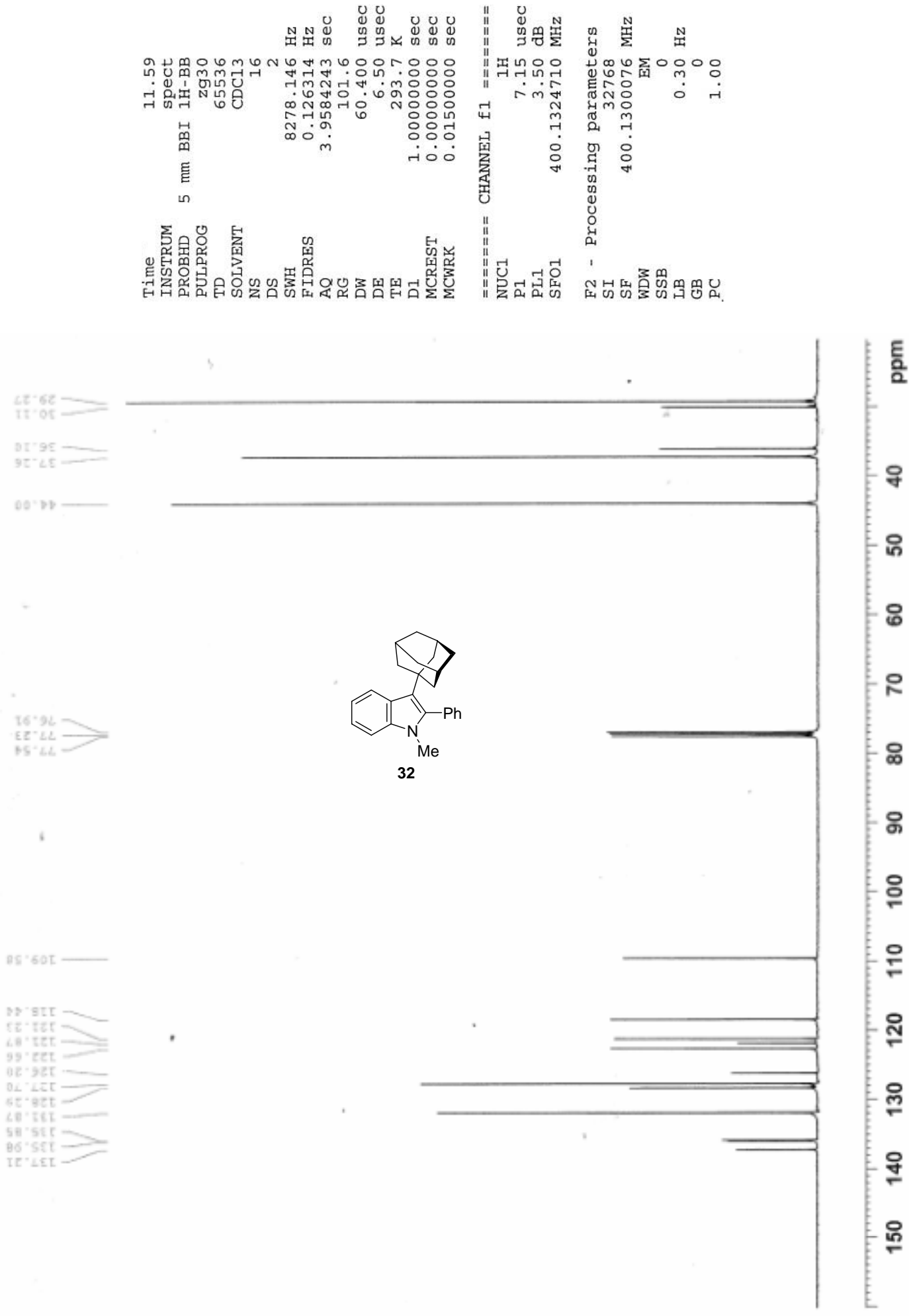

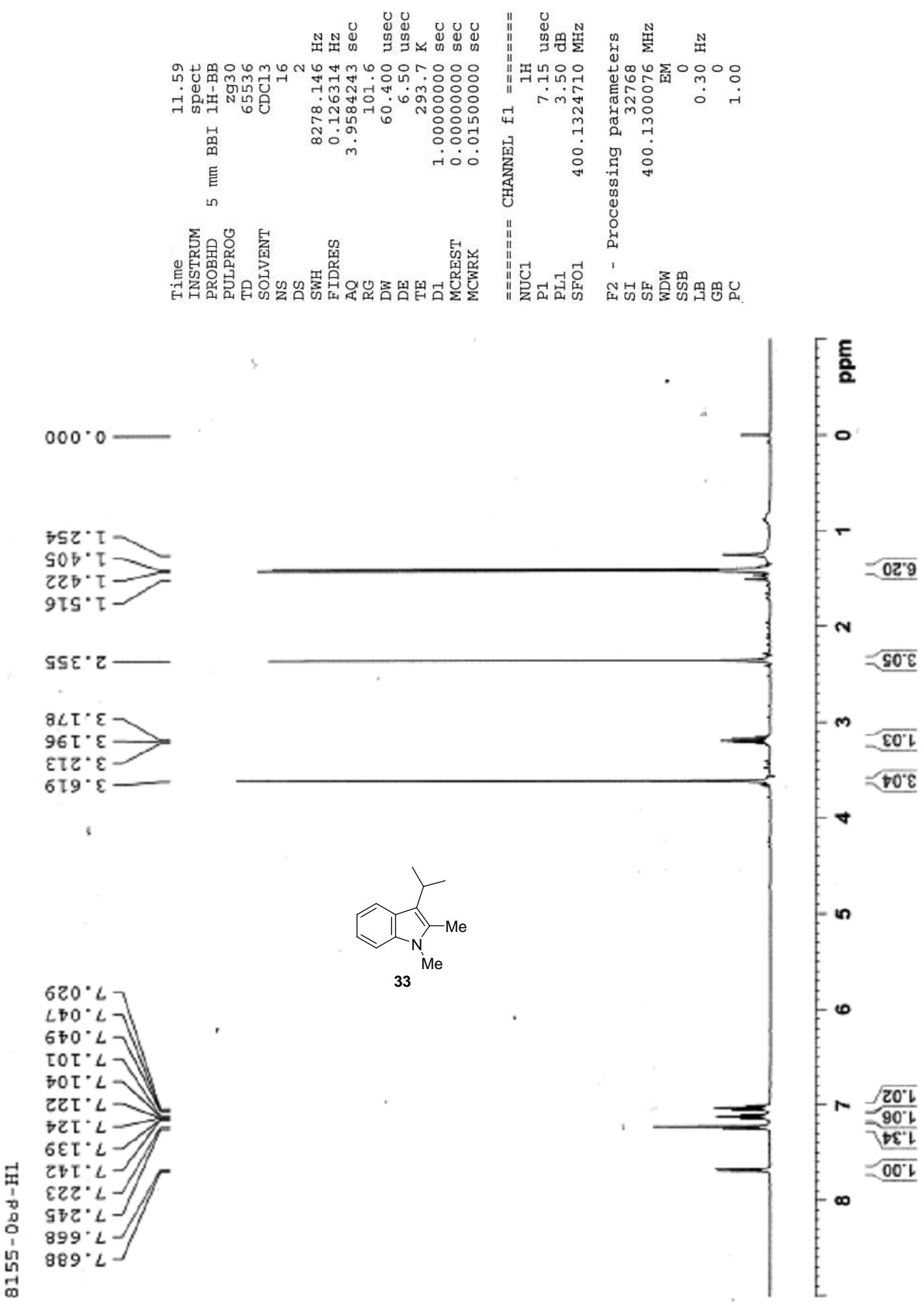
proton NMR spectra of 34and 38 Scheme 3.
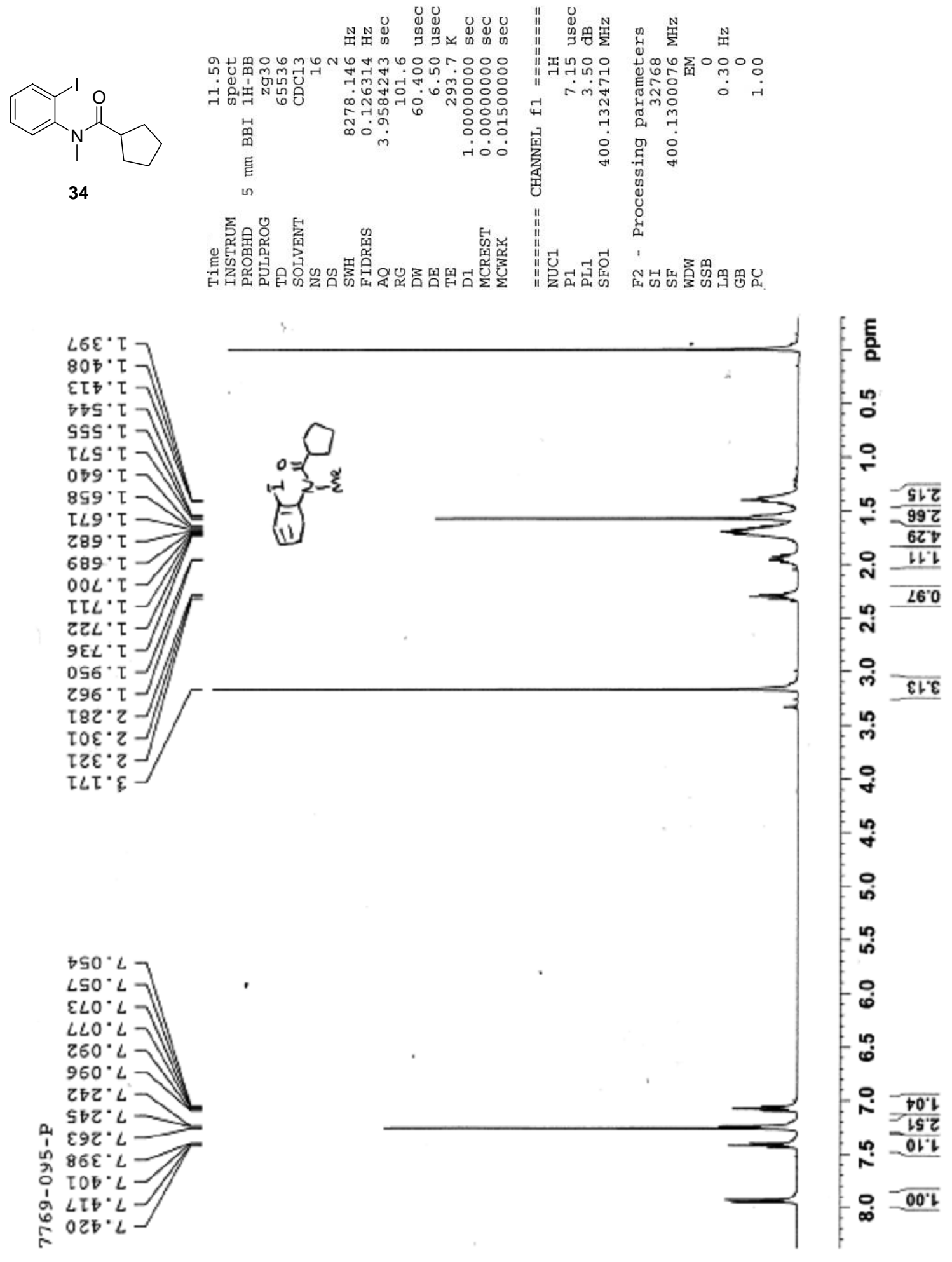

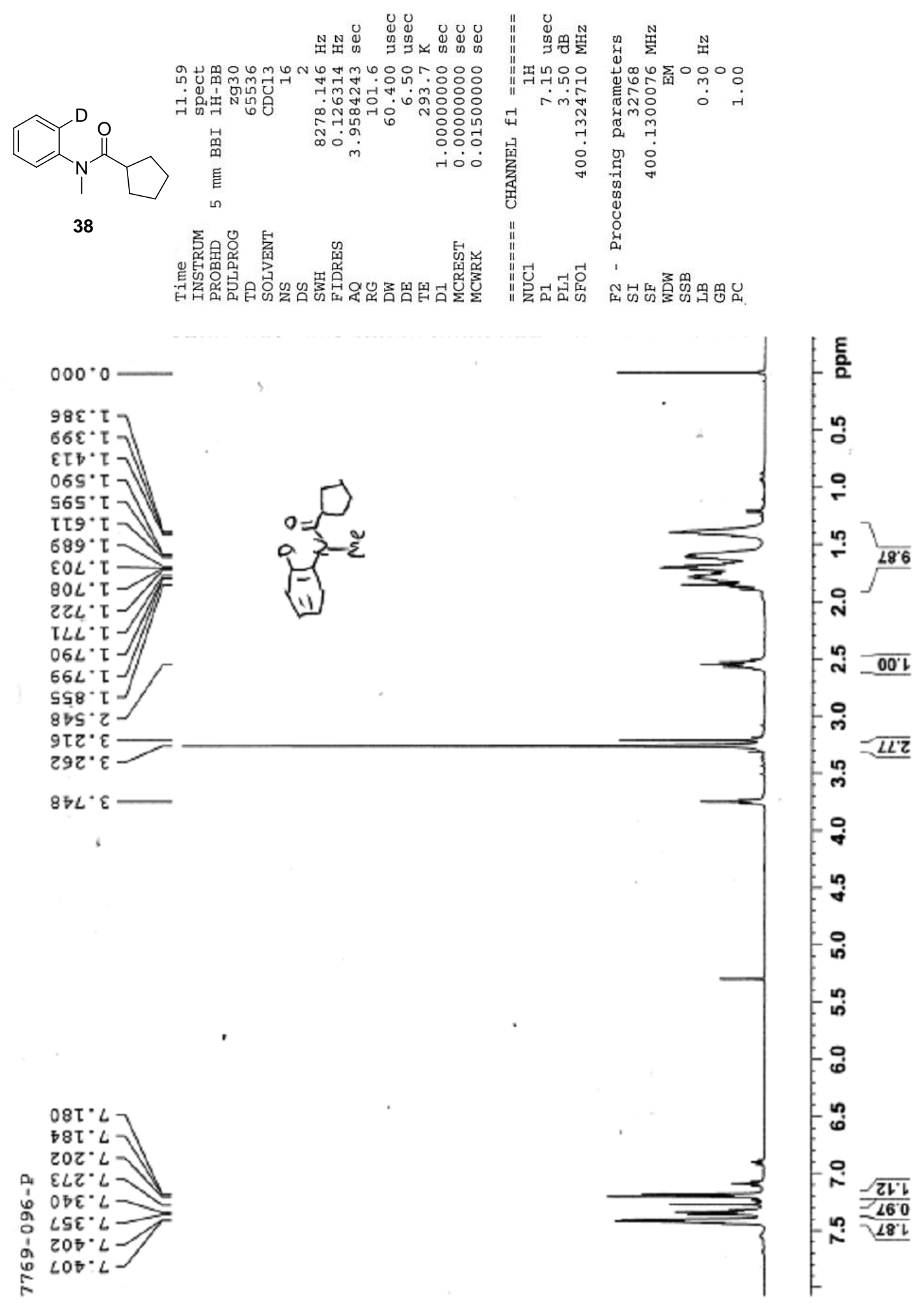
proton NMR spectra of $\mathbf{3 5}$ and $\mathbf{3 9}$ in Scheme 3.
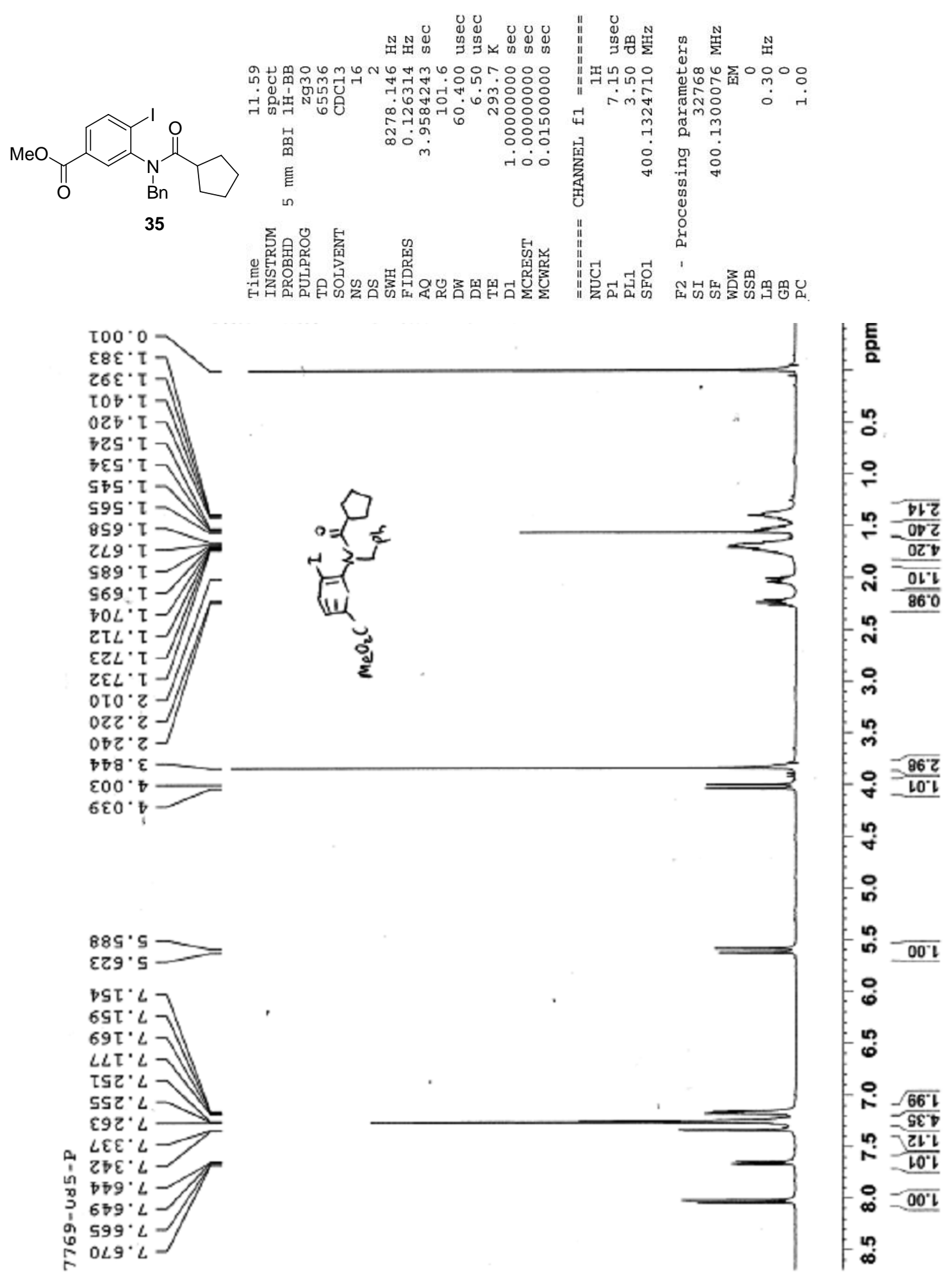

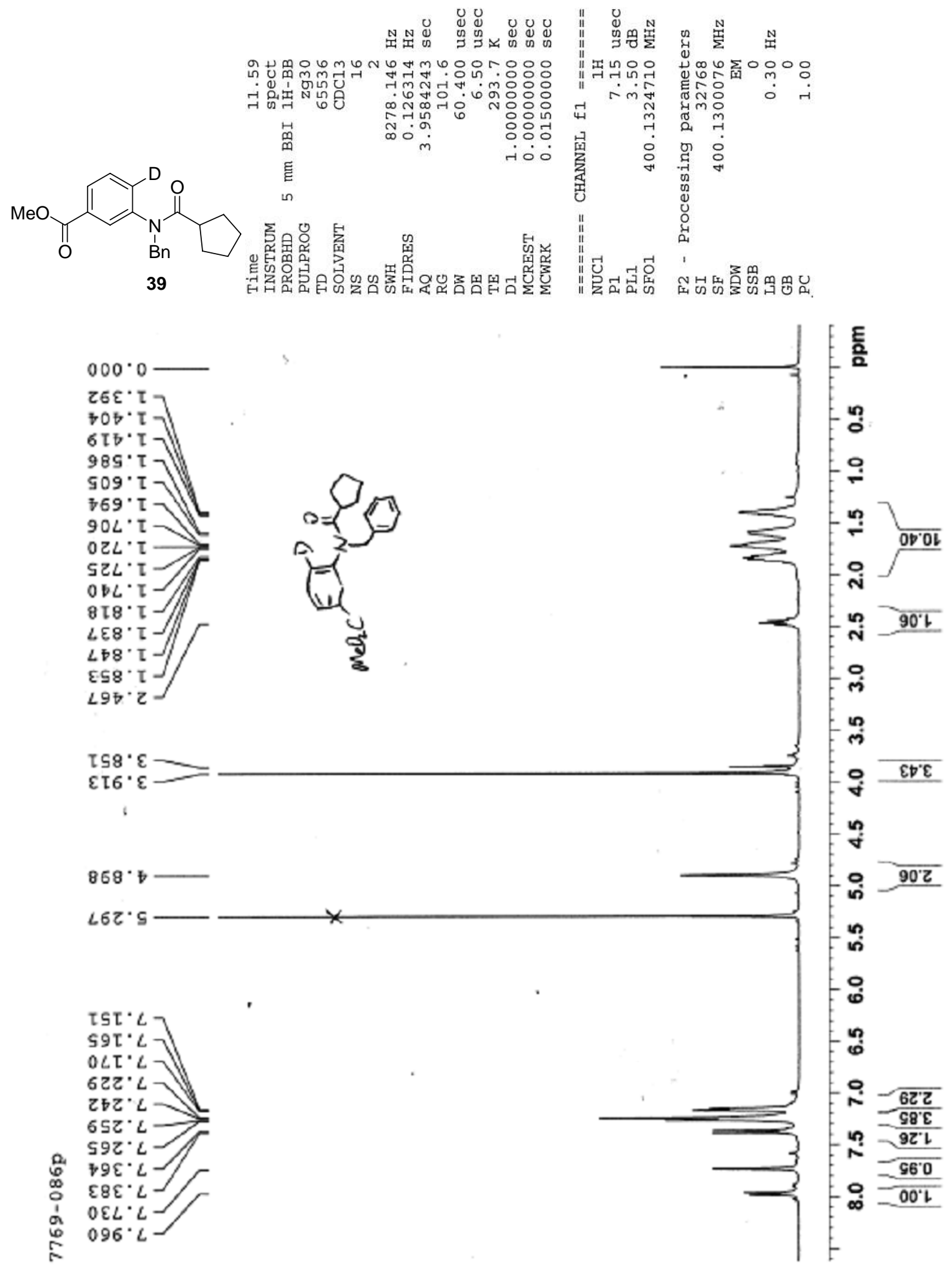